\title{
HIV-1 Tat and Morphine Differentially Disrupt Pyramidal Cell Structure and Function and Spatial Learning in Hippocampal Area CA1: Continuous versus Interrupted Morphine Exposure
}

\author{
DWilliam D. Marks, ${ }^{1}$ Jason J. Paris, ${ }^{2}$ Aaron J. Barbour, ${ }^{3}$ Jean Moon, ${ }^{1}$ Valerie J. Carpenter, ${ }^{1}$ \\ Virginia D. McLane, ${ }^{1}$ Arianna R. S. Lark, ${ }^{1}$ Sara R. Nass, ${ }^{1}$ Jingli Zhang, ${ }^{1}$ Viktor Yarotskyy, ${ }^{1}$ \\ A. Rory McQuiston, ${ }^{3}$ Pamela E. Knapp, ${ }^{1,3,4}$ and ${ }^{\circ}$ Kurt F. Hauser ${ }^{1,3,4}$
}

https://doi.org/10.1523/ENEURO.0547-20.2021

${ }^{1}$ Department of Pharmacology and Toxicology, Virginia Commonwealth University, School of Medicine, Richmond, VA 23298-0613, ${ }^{2}$ Department of BioMolecular Sciences, University of Mississippi, School of Pharmacy, University, MS 38677-1848, ${ }^{3}$ Department of Anatomy and Neurobiology, Virginia Commonwealth University, Richmond, VA 232980709, and ${ }^{4}$ Institute for Drug and Alcohol Studies, Virginia Commonwealth University, Richmond, VA 23298-0709

\begin{abstract}
About half the people infected with human immunodeficiency virus (HIV) have neurocognitive deficits that often include memory impairment and hippocampal deficits, which can be exacerbated by opioid abuse. To explore the effects of opioids and HIV on hippocampal CA1 pyramidal neuron structure and function, we induced HIV-1 transactivator of transcription (Tat) expression in transgenic mice for $14 \mathrm{~d}$ and co-administered time-release morphine or vehicle subcutaneous implants during the final 5 d (days 9-14) to establish steady-state morphine levels. Morphine was withheld from some ex vivo slices during recordings to begin to assess the initial pharmacokinetic consequences of opioid withdrawal. Tat expression reduced hippocampal CA1 pyramidal neuronal excitability at lower stimulating currents. Pyramidal cell firing rates were unaffected by continuous morphine exposure. Behaviorally, exposure to Tat or high dosages of morphine impaired spatial memory. Exposure to Tat and steadystate levels of morphine appeared to have largely independent effects on pyramidal neuron structure and function, a response that is distinct from other vulnerable brain regions such as the striatum. By contrast, acutely withholding morphine (from morphine-tolerant ex vivo slices) revealed unique and selective neuroadaptive shifts in CA1 pyramidal neuronal excitability and dendritic plasticity, including some interactions with Tat. Collectively, the results show that opioid-HIV interactions in hippocampal area CA1 are more nuanced than previously assumed, and appear to vary depending on the outcome assessed and on the pharmacokinetics of morphine exposure.
\end{abstract}

\section{Significance Statement}

Human immunodeficiency virus (HIV), transactivator of transcription (Tat), transgenic mice were co-exposed to morphine to explore opioid-HIV interactions in hippocampal area CA1. Spatial memory was impaired by both Tat and morphine. Tat expression reduced the firing rate of hippocampal CA1 pyramidal neurons at lower stimulating currents regardless of morphine exposure. Exposure to Tat and steady-state levels of morphine acted in a largely independent manner to alter pyramidal neuron structure, function, and associated behavior. This makes CA1 distinct from other regions such as the striatum. Alternatively, withholding morphine (from morphine-tolerant ex vivo slices) revealed unique, but subtle, neuroadaptive shifts in pyramidal neuronal excitability and dendritic plasticity, suggesting that opioid-HIV interactions in the hippocampus are markedly influenced by the pharmacokinetics of opioid exposure. 
Key words: drug abuse; hippocampal CA1 pyramidal neurons; learning and memory; neuro-acquired human immunodeficiency syndrome (neuroHIV); neuroadaptation to opioid exposure; synaptodendritic degeneration and dysfunction

\section{Introduction}

Human immunodeficiency virus-1 (HIV-1) infection results in neurocognitive impairments collectively termed HIV-associated neurocognitive disorders (HAND). Diminished spatial and verbal memory, frequently associated with hippocampal dysfunction, are hallmarks of HAND (Maki et al., 2009; Meyer et al., 2013; Keutmann et al., 2017). These and other deleterious HIV-related outcomes are aggravated by opiate abuse (Lucas et al., 2002; Denis et al., 2019). The opioid epidemic, which has partially driven the HIV pandemic (Nath et al., 2002; Campbell et al., 2017; Fitting et al., 2020), may impede current goals to eradicate HIV within 10 years (Fauci et al., 2019; Lerner and Fauci, 2019). Despite the prevalence of people infected with HIV (PWH) who are chronically exposed to opiates, the mechanisms underlying the neuropathological effects of HIV and morphine are incompletely understood.

The HIV-1 regulatory protein, transactivator of transcription (Tat), is intrinsically neurotoxic and has been shown to impair spatial memory in mice (Carey et al., 2012; Kesby et al., 2016; Marks et al., 2016). Morphine exerts similar antimnemonic effects (Zhu et al., 2011; Kitanaka et al., 2015). Previous work has identified HIV-1 Tat-induced reductions of long-term potentiation (LTP) in CA1 pyramidal neurons, which coincided with spatial memory deficits in Tat transgenic mice ( $\mathrm{Li}$ et al., 2004; Fitting et al., 2013). This prior work showed only modest changes in synaptic spine density and no differences in excitatory synaptic protein content. However, Tat markedly reduced expression of synaptotagmin 2 (Syt2), while triggering presumably compensatory increases in

Received December 16, 2020; accepted March 10, 2021; First published March 26, 2021.

The authors declare no competing financial interests.

Author contributions: W.D.M., J.J.P., and K.F.H. designed research; W.D.M., J.J.P., A.J.B., J.M., V.J.C., V.D.M., S.R.N., J.Z., and V.Y. performed research; W.D.M., J.J.P., A.J.B., J.M., V.J.C., V.D.M., A.R.S.L., S.R.N., J.Z., V.Y., A.R.M., P.E.K., and K.F.H. analyzed data; W.D.M., J.J.P., V.D.M., A.R.M., P.E.K., and K.F.H. wrote the paper.

This work was supported by National Institutes of Health Grants R01 DA018633 (to K.F.H.), R00 DA039791 (to J.J.P.), R01 MH107507 (to A.R.M.), R01 DA034231 (to P.E.K. and K.F.H.), K02 DA027374 (to K.F.H.), F31 DA047195 (to A.J.B.), F32 DA047193 (to V.D.M.), and T32 DA007027.

Acknowledgements: We thank the National Institute on Drug Abuse.

W. D. Marks' present address: Department of Psychiatry, University of Texas Southwestern Medical Center, Dallas, TX 75235.

A. J. Barbour's present address: Department of Neurology, University of Pennsylvania, Philadelphia, PA 19104.

J. Moon's present address: Department of Pharmacology, Case Western Reserve University School of Medicine, Cleveland, $\mathrm{OH} 44106$.

Correspondence should be addressed to Kurt F. Hauser at kurt.hauser@ vcuhealth.org.

https://doi.org/10.1523/ENEURO.0547-20.2021

Copyright (c) 2021 Marks et al.

This is an open-access article distributed under the terms of the Creative Commons Attribution 4.0 International license, which permits unrestricted use, distribution and reproduction in any medium provided that the original work is properly attributed. gephyrin postsynaptically, suggesting losses in inhibitory GABAergic transmission within CA1 (Fitting et al., 2013). This selective vulnerability of interneurons within the CA1 may lower the threshold of excitation, leading to an increased likelihood of excitotoxicity. Dysregulation of excitatory/inhibitory tone may involve specific interneuronal subtypes and microcircuits (Fitting et al., 2013; Marks et al., 2016).

Opioid use disorder (OUD) can promote neurodegeneration within the hippocampus and other brain regions. Chronic abuse was found to accelerate Alzheimer's disease-like pathology in multiple brain areas including the hippocampus of HIV-negative individuals in a cohort of preferential opiate misusers in Edinburgh, Scotland (Ramage et al., 2005; Anthony et al., 2010; Kovacs et al., 2015). This includes increases in hyperphosphorylated $\operatorname{tau}, \operatorname{GSK} 3 \beta$, and CDK5 levels, as well as microgliosis (Anthony et al., 2010). Within the hippocampus, opiate abuse alters CA1 ensemble activity (Liu et al., 2010) and impairs CA3-CA1 LTP (Borjkhani et al., 2018). Opiate abuse is linked to white matter damage (Li et al., 2016) and increased systemic inflammation (Piepenbrink et al., 2016). Even among PWH treated with combination antiretroviral therapy (cART), OUD (which often includes cocaine co-exposure) worsens HAND symptomatology, including deficits in verbal and working memory (Byrd et al., 2011, 2012; Meyer et al., 2013) and decision-making (Vassileva et al., 2013). Within the microcircuitry of hippocampal subregions, opiates and Tat may exert unique interactions. Morphine generally decreases interneuron excitability (Liao et al., 2005; McQuiston, 2008; Xu et al., 2013; Fitting et al., 2015); however, morphine's capacity to inhibit GABAergic interneuronal inputs onto pyramidal cells may also exacerbate Tat-induced excitotoxicity. These outcomes are dependent on neuronal type and opioid receptor distribution (Drake and Milner, 2002; Liao et al., 2005; McQuiston, 2007, 2008; Xu et al., 2013).

OUD can exacerbate HIV-induced neuropathology across multiple brain regions (Fitting et al., 2010a, 2014, 2020; Hauser et al., 2012; Hahn et al., 2016), although because of the regional differences in the development of HIV-induced pathology and $\mu$-opioid receptor (MOR) expression, each brain region is anticipated to display unique pathologic interactions and rates of decline (Fitting et al., 2010b). Given the Tat-mediated deficits previously observed in the GABAergic network of the mouse hippocampus, we hypothesized that the expression of Tat would disrupt the functional output of CA1, and that morphine would exacerbate these effects. We further expected that the reduction of Syt2 in the stratum radiatum (SR) layer of CA1 would result in a loss of synaptic contacts on pyramidal cells. To test these hypotheses, control and Tat transgenic mice were implanted with subcutaneous vehicle or morphine $(25 \mathrm{mg})$ time-release implants. Mice were assessed for effects on spatial memory and motor behavior. Opioid injection drug use is 
accompanied by fluctuating drug levels (Kreek, 1987, 2001; Kreek et al., 2002) resulting in three to four bouts of "relative withdrawal" per day between injections (Reisine and Pasternak, 1996). To begin to assess the initial pharmacokinetic consequences of opioid withdrawal, morphine was withheld from some ex vivo slices during recordings. CA1 pyramidal cell function was studied via whole-cell patch-clamp electrophysiology in ex vivo slices in the presence or absence of morphine. Patched pyramidal cells were then visualized via biocytin backfill and 3D reconstruction, and morphology was assessed.

\section{Materials and Methods}

The use of mice in these studies was preapproved by the Institutional Animal Care and Use Committee at Virginia Commonwealth University. Experiments were conducted in accordance with ethical guidelines defined by the National Institutes of Health (NIH Publication No. 85-23).

\section{Subjects and housing}

This study used male mice between 8 and 12 weeks of age with or without the presence the HIV-1 tat transgene (HIV-1 Tat $\left.{ }_{1-86}\right)$ under the control of a doxycycline (Dox)activated Tet-on expression system driven by a glial fibrillary acidic protein (GFAP) promoter (Bruce-Keller et al., 2008). Dox was administered in a specially formulated diet (Dox Diet \#2018, $6 \mathrm{~g} / \mathrm{kg}$, Harlan Laboratories) to the mice for $14 \mathrm{~d}$, after which tissues were harvested for biochemical or electrophysiological experiments. All mice were housed four to five per cage and maintained in a temperature-controlled and humidity-controlled room on a 12/12 h light/dark cycle (lights off at 6 P.M.) with food and water available ad libitum. On day 5 of Dox administration, vehicle or morphine pellets (25-mg morphine sulfate, NIDA Drug Supply System) were implanted subcutaneously.

\section{Surgical procedure}

Subcutaneous vehicle-containing or morphine-containing pellets were implanted in Tat $-\left(n_{\text {vehicle }}=17, n_{\text {morphine }}=15\right)$ and Tat $+\left(n_{\text {vehicle }}=18, n_{\text {morphine }}=15\right)$ mice under isoflurane anesthesia (2.5-4\%) as described previously (Fitting et al., 2016). Following surgery, mice were monitored for $96 \mathrm{~h}$ to ensure weight gain, muscle tone, proper neurologic responses, and general health (Crawley and Paylor, 1997). All mice in the present study recovered.

\section{Ex vivo slice preparation for electrophysiological experiments}

Following $14 \mathrm{~d}$ of Dox exposure, adult male mice were over-anesthetized with isoflurane anesthesia (5\%), euthanized, and transcardially perfused with sucrose cutting media (3 mm KCl, $4.12 \mathrm{~mm} \mathrm{MgSO}$, $1.2 \mathrm{~mm} \mathrm{NaH}_{2} \mathrm{PO}_{4}, 206$ $\mathrm{mm}$ sucrose, $25 \mathrm{~mm} \mathrm{NaHCO}_{3}$, and $25 \mathrm{~mm}$ glucose) chilled to $1-3^{\circ} \mathrm{C}$ and bubbled with a $5 \% \mathrm{CO}_{2}$ balanced oxygen mix. Brains were dissected, bisected midsagittally, and $350-\mu \mathrm{m}$-thick, horizontal sections were cut from the ventral surface using a Leica VT1200 S vibratome (Leica Biosystems). Slices were cut in oxygenated sucrose cutting media held at $1-3^{\circ} \mathrm{C}$ by an external cooling apparatus (Huber), then transferred onto a nylon mesh submerged in oxygenated extracellular recording solution (3 mм KCl, $1.2 \mathrm{~mm} \mathrm{CaCl} 2,1.2 \mathrm{~mm} \mathrm{MgSO}_{4}, 1.2 \mathrm{~mm} \mathrm{NaH}_{2} \mathrm{PO}_{4}$, $125 \mathrm{~mm} \mathrm{NaCl}, 25 \mathrm{~mm} \mathrm{NaHCO}_{3}$, and $25 \mathrm{~mm}$ glucose) and maintained at $36.5^{\circ} \mathrm{C}$ for $30 \mathrm{~min}$. In slices in which morphine is maintained (not withheld), the cutting solution and extracellular solution were supplemented with $500 \mathrm{~nm}$ morphine sulfate. The beaker was then returned to room temperature and the slices allowed to rest for $30 \mathrm{~min}$ before recording. In parallel experiments, morphine sulfate was withheld from the cutting and extracellular solutions to model acute $(2-4 \mathrm{~h})$ withdrawal in morphine-pelleted mice.

\section{Electrophysiological recording}

Slices were continuously perfused with extracellular recording solution warmed to $30-34^{\circ} \mathrm{C}$ with an external heating apparatus (Warner Instruments, TC-344B). The CA1 subfield of the hippocampus was visualized using a $4 \times$ magnification objective on a Zeiss Axio Examiner A1 microscope (Zeiss). Magnification was switched to a $63 \times$ fluid-immersion objective to identify putative pyramidal neurons in the CA1 pyramidal layer. Pipettes for wholecell patch-clamp physiology were pulled (Narishige PC10 pipette puller; Narishige) from borosilicate glass pipettes (WPI \#1B1505-4, World Precision Instruments) to a resistance of 2-6 M $\Omega$. Pipettes were filled with an intracellular solution containing $135 \mathrm{~mm} \mathrm{KMeSO}_{4}, 10 \mathrm{~mm} \mathrm{HEPES}$, $2 \mathrm{~mm}$ MgATP, $0.1 \mathrm{~mm}$ NaGTP, $8 \mathrm{~mm} \mathrm{NaCl}, 0.1 \mathrm{~mm}$ BAPTAK $_{4}$, and $0.2 \%$ biocytin (pH 7.25). Membrane potentials were recorded using a MultiClamp 700B amplifier (Molecular Devices), processed using a Digidata 1550A digitizer, and analyzed using Clampex 10.4 software (Molecular Devices) on a Microsoft Windows-based computer. Membrane potentials were observed in response to stepwise, 25-pA current increases from -100 to 400 pA.

\section{Histologic processing of biocytin-filled pyramidal cells}

After completion of electrophysiological recordings, slices containing biocytin-filled cells were moved into a 24well plate and fixed with $4 \%$ paraformaldehyde in $1 \times$ PBS for $4-7 \mathrm{~d}$ at $4^{\circ} \mathrm{C}$. Following fixation, slices were rinsed in PBS six times for $10 \mathrm{~min}$ each on a rocking platform at $4^{\circ}$ C. Slices were permeabilized for $30 \mathrm{~min}$ in a solution of $50 \%$ ethanol in $1 \times$ PBS, containing $0.02 \%$ Triton X-100, then transferred into a similar solution containing $70 \%$ ethanol for $30 \mathrm{~min}$, and returned to $50 \%$ ethanol for $30 \mathrm{~min}$. Slices were rinsed as described earlier, and then blocked in PBS containing 2\% normal chicken serum, $0.02 \%$ bovine serum albumin, and $0.02 \%$ Triton $X-100$ for $30 \mathrm{~min}$. Primary antibodies against gephyrin (goat polyclonal, 1:1000, Sc-6411, Santa Cruz) were applied, and slices were incubated for $48 \mathrm{~h}$ on a rocking platform at $4^{\circ} \mathrm{C}$. The slices were rinsed as before and incubated in secondary antibodies (donkey anti-goat IgG-Alexa Fluor 488 1:500, Invitrogen A1055; goat anti-rabbit IgG-Alexa Fluor 647 1:500, Invitrogen A-21244), as well as an Alexa Fluor 594-conjugated streptavidin probe to label biotin (1:100, 
Invitrogen, S-32356) for $48 \mathrm{~h}$, and then rinsed in PBS. Slices were incubated in Hoechst 33342 at room temperature $(0.5 \mu \mathrm{g} / \mathrm{ml}$ in PBS; Invitrogen, H3570) for $10 \mathrm{~min}$, rinsed in PBS, and mounted on slides using ProLong Gold Antifade reagent (Invitrogen, P36930).

\section{Imaging, 3D reconstruction, and analysis of biocytin- filled pyramidal cell dendrites}

Z-stack 3D imaging of neurons was performed using a Zeiss LSM 700 at 20× (plan-apochromat 0.8NA, M27) and $63 \times$ (plan-apochromat 1.40 NA oil immersion DIC, M27) magnification (Zeiss). Hoechst 33342 was visualized using a $405 \mathrm{~nm}$ laser with a SP 490-nm filter, Alexa Fluor 488 using a 488-nm laser and a BP 490- to 555-nm filter, and Alexa Fluor 594 using a 555-nm laser with the variable secondary dichroic (VSD) beamsplitter set at $585 \mathrm{~nm}$. Zstack data were reconstructed into a $3 D$ image using Imaris Bitplane 7.6.4. Primary dendrites were defined as dendrites that protrude from the cell body, with dendritic order increased by every branching point. Dendritic spine analysis was performed by a blinded observer using Imaris Bitplane 7.6.4 and regions selected for analysis were $20-30 \mu \mathrm{m}$ in length and were selected at a 5- to 10$\mu \mathrm{m}$ distance from the previous branch point and at least $5 \mu \mathrm{m}$ from the next branch point. Dendritic spine densities are reported as the average number of spines per $10-\mu \mathrm{m}$ length of dendrite/cell. Spine morphology was analyzed using uncompressed Z-stacks. Spines were counted along 20 - to $30-\mu \mathrm{m}$-long dendrite segments parallel to the plane of view. The dendritic spine density determinations of the vehicle versus the morphine-replete groups, and the vehicle versus the morphine-withheld groups, were performed separately by separate individuals. Accordingly, the spine densities in the vehicle (control) groups in the morphine-replete and morphine-withheld groups differ from one another.

\section{Quantification of spine subtypes using Image J}

In brief, mushroom, stubby, and thin/filopodial subtypes were identified in fluorescent images by a blinded observer, as described previously (Schier et al., 2017). Dendritic spines along a $\sim 30 \mu \mathrm{m}$ segment of dendrite parallel to the plane of the $z$-slice were counted. Dendritic segments were analyzed within the stratum oriens (SO), $\mathrm{SR}$, and stratum lacunosum moleculare (SL-M) anatomic strata of backfilled CA1 pyramidal neurons. Data are expressed as number of spines/10- $\mu \mathrm{m}$ length of dendrite from individual cells.

\section{Quantification of inhibitory puncta}

Analysis of inhibitory puncta associated with specific neurite segments was performed using the co-localization module of Imaris Bitplane (version 9.0). Briefly, background signal was filtered out of the 488-nm channel (gephyrin), and the signal from the 594-nm channel (streptavidin-tagged pyramidal cells) was used as a mask to create a co-localization channel for gephyrin positive puncta occurring within spaces occupied by filled pyramidal cells. The number of puncta was quantified along $\sim 10 \mu \mathrm{m}$ of the identified neurite segment. Data are expressed as the number of gephyrin-labeled puncta per micrometer. Analysis of inhibitory contacts took place on the aspinous portions of the apical and basilar dendrites immediately adjacent to the cell body, as well as the spiny portions at the distal ends of dendrites terminating in SL$M$, as these dendritic compartments have the greatest percentage of extant inhibitory contacts on a "representative" CA1 pyramidal cell (Megías et al., 2001).

\section{Stereology}

The volume fraction $\left(V_{v}\right)$ of hippocampal areas CA1, CA2, CA3, and the dentate gyrus were assessed stereologically. Tat- and Tat $+(n=5-6)$ mice were administered vehicle or 25-mg morphine (data not shown) time-release pelleted implants, perfused with 4\% PFA and frozen at $-80^{\circ} \mathrm{C}$. Frozen hippocampal sections were sectioned 40 $\mu \mathrm{m}$ thick in the coronal plane and stained with Hoechst 33342 (1:20,000 in PBS, 8 min at room temperature). Left hemispheres were imaged at $10 \times$ magnification and montaged using a Zeiss Axio-Observer Z1 microscope with a motorized stage encoder and computerized tile reconstruction (Zeiss, Zen Black 2.3). $V_{V}$ was estimated using point count analysis and a standardized grid overlay (per Cavalieri's principle; West et al., 1991; Calhoun et al., 1998; Mouton, 2002, 2014).

\section{Barnes maze task}

All behavioral testing was conducted in the presence of 70-dB white noise with mice habituated to the testing room for $1 \mathrm{~h}$ before assessments. Behavioral data were recorded and digitally encoded using an ANY-maze animal tracking system (Stoelting Co).

Mice were assessed for spatial learning and motor function via the Barnes maze (Barnes, 1979) as modified from previously reported methods (Marks et al., 2016). After a day of surgical recovery, mice were prehabituated to the maze (day 1 ) followed by $4 \mathrm{~d}$ of testing (two trials per day over days 2-5), and a 1-d reversal probe trial (two trials on day 6). Briefly, on day 1 , mice were prehabituated to a random escape hole for $2 \mathrm{~min}$, then were placed in the brightly lit center of the Barnes maze $(91-\mathrm{cm}$ diameter, $90-\mathrm{cm}$ height, with 20 holes, each $5-\mathrm{cm}$ diameter; Stoelting (Co) and guided to the escape hole where they remained for $2 \mathrm{~min}$. Lastly, mice were placed under a glass cylinder next to the escape hole and allowed to volitionally enter ( $3 \mathrm{~min}$ max. latency), or were guided in, and remained for $2 \mathrm{~min}$. On testing days, mice were placed in the brightly lit center of the Barnes maze and allowed up to $3 \mathrm{~min}$ to find an open escape hole (escape-hole quadrant counterbalanced across testing groups). Mice that did not enter the hole were gently guided to the hole and allowed to remain for $2 \mathrm{~min}$. On the final day of testing, a reversal probe trial was conducted such that the correct goal box was rotated $180^{\circ}$ from its original position. The mean response of both trials was analyzed on each day for all mice. Shorter latencies to find the escape hole, a greater proportion of time spent in the correct quadrant of the maze, and fewer errors were considered indices of 
greater learning (Camara et al., 2013). Distances and velocities traveled were used as motor indices (Marks et al., 2016).

\section{Vision testing}

All mice were tested for visual function following conclusion of the Barnes maze test (Wersinger et al., 2002; Marks et al., 2016). Briefly, mice were suspended $\sim 30.5 \mathrm{~cm}$ above a vertical ring-stand and were lowered with the ring-stand $\sim 5 \mathrm{~cm}$ from the left or right visual field (close enough to allow visual, but not whisker, contact with the ring-stand). The left and right visual fields were assessed for each mouse, with the starting side counterbalanced across groups. Visual responding was considered positive when mice reached with the forepaws for the rod when presented to both the left and right side. A response to only one visual field is considered a negative response. One male animal (Tat + /morphine) failed vision testing and was excluded from analyses.

\section{Statistical analyses}

Electrophysiological measures were assessed via repeated measures ANOVA (firing frequency) or two-way ANOVA (intrinsic membrane properties) with current step as the within-subjects factor ( $0-400 \mathrm{pA})$, and tissue genotype (Tat- or Tat + ) and drug treatment combination (vehicle-exposed tissues, morphine-exposed tissue in morphine-free solution, or morphine-exposed tissue in morphine-replete solution) as the between-subjects factors. A priori planned comparisons were conducted on all electrophysiological data with morphine-exposed Tatand Tat + tissues (maintained in either morphine-replete or morphine-withheld solution), compared with their respective vehicle controls, with Bonferroni corrections for multiple comparisons applied. The density of dendritic spines was assessed separately by spine type via twoway ANOVA with tissue genotype (Tat- or Tat + ) and drug treatment combination (vehicle-exposed tissues, morphine-exposed tissue in morphine-free solution, or morphine-exposed tissue in morphine-replete solution) as the between-subjects factors. Fisher's protected least significant difference (PLSD) post hoc tests were used to assess group differences following main effects. Interactions were delineated via simple main effects and main effect contrasts that were $\alpha$ corrected for multiple comparisons. Behavioral data were assessed via repeated-measures ANOVA with Barnes maze testing trial (testing days 1-4 and reversal probe) as the within-subjects factor, and both mouse genotype (Tat - or Tat + ) and drug treatment (morphine or vehicle) as the between-subjects factors. Fisher's PLSD post hoc tests were used to assess group differences following main effects. Interactions were delineated via simple main effects and main effect contrasts that were $\alpha$ corrected for multiple comparisons. Effect size measures $\left(\eta^{2}\right.$, Cohen's $\left.d\right)$ are presented following omnibus inferential statistics and main effect contrasts, respectively. All analyses were considered significant when $p<0.05$.

\section{Results}

\section{Morphine and Tat influence the electrophysiological properties of CA1 pyramidal cells}

We used whole-cell patch-clamp physiology to examine the firing frequency and other electrophysiological properties of CA1 pyramidal cells, as they represent the focal point of inhibitory and excitatory processing in the region before projecting out toward the entorhinal cortex. To assess the effects of Tat and morphine on physiological function of CA1 pyramidal cells as the functional output of CA1, a planned comparison testing approach was applied to assess the statistical differences between six sets of conditions: Tat - and Tat + vehicle-treated mice ( $n=13$ cells from three mice, and 11-12 cells from three mice, respectively), Tat - and Tat + morphine-treated mice in which the ex vivo slices were continuously maintained in 500 пм morphine-containing physiological solutions during recordings and referred to as "morphine replete" ( $n=19$ cells from 4 mice, and 13 cells from 4 mice, respectively), and Tat - and Tat + morphine-treated mice in which morphine was withheld from the ex vivo slices that were maintained in physiological solutions lacking morphine during recordings and referred to as "morphine withheld" ( $n=29$ cells from 8 mice, and 22 cells from 7 mice, respectively). Tat - and Tat + vehicletreated mice were independently compared with morphine-replete groups or to morphine-withheld groups, but morphine-replete and morphine-withheld groups were not directly compared with one another.

When comparing Tat - and Tat + vehicle-treated mice to Tat- and Tat + morphine-replete mice, several effects were observed (Fig. 1A,C,E-G). Repeated-measures assessment of firing frequency showed a significant interaction between current step and Tat genotype $\left(F_{(15,780)}=3.04, p<0.05 ; \eta^{2}=0.007\right.$; Fig. $1 A, C)$. Post hoc contrasts revealed that between the 50- and 150-pA current steps, pyramidal cells from Tat + mice fired at a lower frequency than those from Tat- mice ( $p=0.002-0.046$; Cohen's $d=0.5-0.8$; Fig. $1 C, D)$. Intrinsic membrane properties were assessed by two-way ANOVA. An interaction between Tat and morphine exposure was observed in the resting membrane potential of the CA1 pyramidal cells $\left(F_{(1,53)}=\right.$ 7.34, $p<0.05 ; \eta^{2}=0.12$ ). Pairwise comparisons using the Bonferroni correction for multiple comparisons (significance threshold set at $p<0.008$ ) revealed that only vehicle-treated Tat - and Tat + mice differed (Fig. $1 E)$, with Tat + vehicle-treated mice having significantly more depolarized resting membrane potentials $(p=0.006$; Cohen's $d=1.2)$. In addition, a main effect of morphine was observed on the firing threshold of CA1 pyramidal cells $\left(F_{(1,53)}=15.81, p<0.05 ; \eta^{2}=\right.$ 0.22 ), with morphine-treated cells firing at a more hyperpolarized potential than vehicle-treated mice $(p=0.001$; Cohen's $d=0.5$; Fig. $1 G)$. No significant effects were noted for the smallest level of current required to elicit firing, or rheobase; however, Tat treatment tended to increase rheobase compared with Tat - controls $\left(F_{(1,53)}=3.37, p=0.062 ; \eta^{2}=0.06\right.$; Fig. $1 F)$. Notably, no significant differences in input 
A

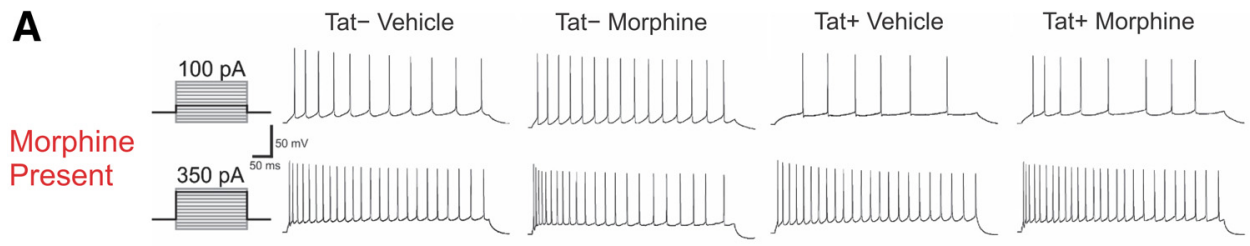

B

Tat- Vehicle Tat-Morph Withheld

Tat+ Vehicle

Tat+ Morph Withheld

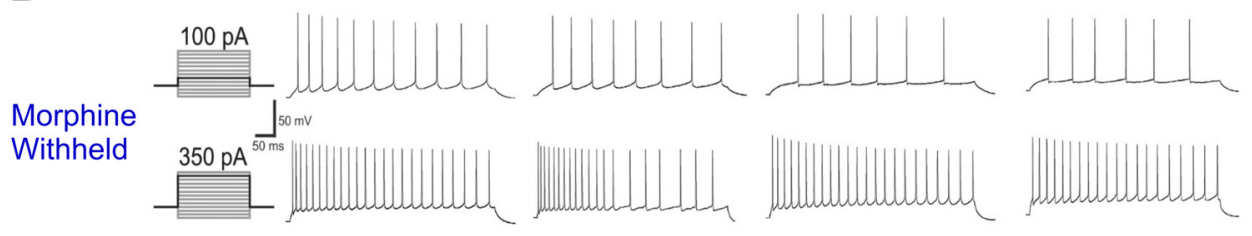

C

D
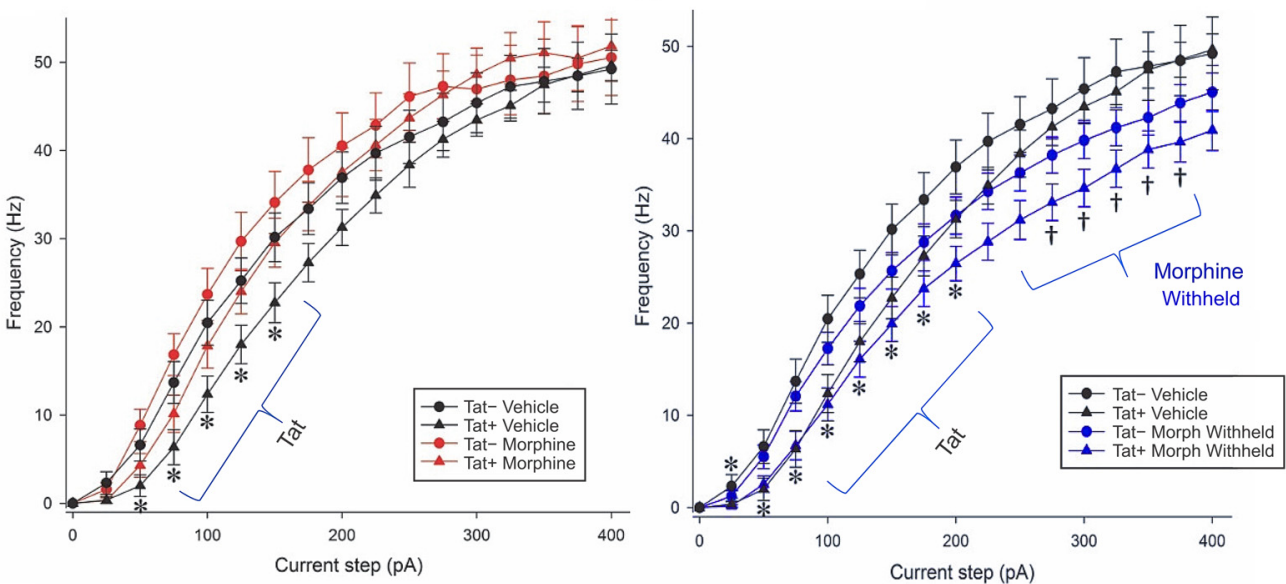

E
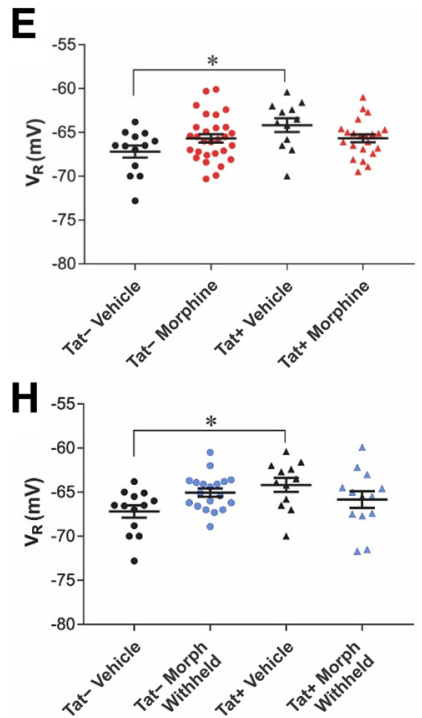

$\mathbf{F}$
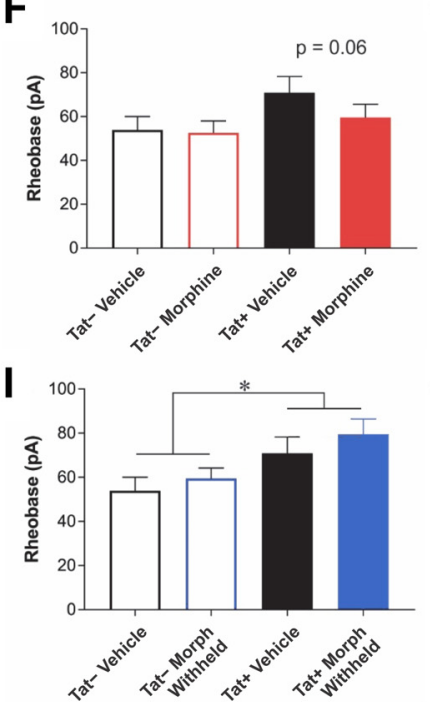

G

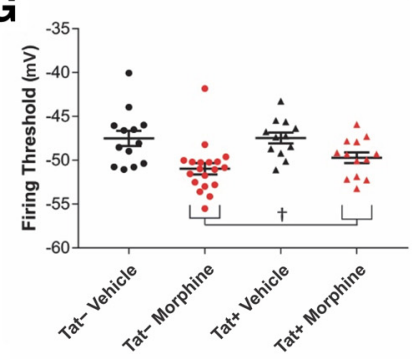

J

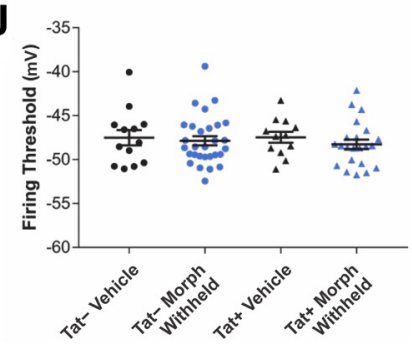

Figure 1. Analysis of the firing frequency of CA1 pyramidal cells from Tat- or Tat + mice treated with vehicle or morphine time-release implants in which morphine is present $(500 \mathrm{~nm})$ or withheld $(0 \mathrm{~nm})$ during the recordings. $\boldsymbol{A}, \boldsymbol{B}$, Representative traces are depicted at the 100- and 350-pA current steps in which morphine (Morph) is present (500 nм; $\boldsymbol{A}$ ) or withheld (0 nм; $\boldsymbol{B})$ during the recordings. A, C, Pyramidal cell firing rates were unaffected by sustained morphine exposure. $\boldsymbol{B}, \boldsymbol{D}$, By contrast, when morphine was withheld during recordings from mice previously maintained on morphine, firing rates were significantly suppressed. $\mathbf{C}, \mathrm{CA} 1$ pyramidal cells from Tat + mice fired at a lower frequency than those of Tat- mice between 50 and 150 pA, but were unaffected by exposure to morphine during recordings $(\boldsymbol{C})$. C, $\boldsymbol{D}$, Tat genotype interacted with the amount of current applied. $\boldsymbol{D}$, Withholding morphine from slices isolated from morphine-exposed mice resulted in significantly lower pyramidal cell firing rates at stimulating currents from 275 to 375 pA compared with morphine-naive cells $\left({ }^{\dagger} p<0.05\right)$; nevertheless, Tat and morphine did not interact statistically perhaps because the effect of withholding morphine was not seen at other stimulating currents and at 25-to 200-pA current 
Table 1: Membrane properties of CA1 pyramidal cells after exposure to Tat and morphine

\begin{tabular}{|c|c|c|c|c|c|c|}
\hline In vivo treatment & $\begin{array}{l}\text { Tat- } \\
\text { Vehicle } n=13\end{array}$ & $\begin{array}{l}\text { Tat }+ \\
\text { Vehicle } n=12\end{array}$ & $\begin{array}{l}\text { Tat }- \\
\text { Morphine } n=19\end{array}$ & $\begin{array}{l}\text { Tat }+ \\
\text { Morphine } n=13\end{array}$ & $\begin{array}{l}\text { Tat }- \\
\text { Morphine } n=29\end{array}$ & $\begin{array}{l}\text { Tat }+ \\
\text { Morphine } n=22\end{array}$ \\
\hline Ex vivo treatment & - & - & Morphine & Morphine & - & - \\
\hline Capacitance (pF) & $130.2 \pm 12.4$ & $175.4 \pm 16.0$ & $157.7 \pm 9.5$ & $138.4 \pm 10.3$ & $166.3 \pm 8.8$ & $184.7 \pm 13.5$ \\
\hline Resistance $(\mathrm{M} \Omega)$ & $182.1 \pm 21.6$ & $154.7 \pm 16.9$ & $146.4 \pm 10.2$ & $127.2 \pm 8.9$ & $179.0 \pm 10.9$ & $149.2 \pm 16.2$ \\
\hline
\end{tabular}

Capacitance and resistance values from pyramidal cell recordings from Tat - and Tat + mice maintained on vehicle (control)-containing or morphine (25 mg)-containing time-release implants in which morphine (500 nм) was present ("morphine") or withheld (-) during recordings in hippocampal slices ex vivo. No significant changes were observed. All values are shown as the mean \pm SEM.

resistance or capacitance were seen in pyramidal cells between any groups (Table 1).

To assess the effects of morphine withdrawal on the physiological response of CA1 pyramidal cells in mice previously exposed to morphine, vehicle-treated cells were compared separately to cells in which morphine (500 nM) was continuously present or absent (withheld) during the recordings (Fig. $1 B, D, H-J)$. Analyses of the firing frequencies revealed two interactions, one between Tat and stimulus current amplitude $\left(F_{(15,1065)}=3.47\right.$, $\left.p<0.05 ; \eta^{2}=0.004\right)$, and another between morphine treatment and stimulus current amplitude $\left(F_{(15,1065)}=\right.$ $6.43, p<0.05 ; \eta^{2}=0.007$; Fig. 1B,D). Post hoc contrasts revealed that Tat exposure altered the firing rate of pyramidal cells depending on the amount of the stimulating current. Tat + pyramidal cells fired at a lower frequency than Tat - neurons $(p=0.001-0.021$; Cohen's $d=0.5-0.8$; Fig. $1 D$ ) at 25-200 pA, although the firing rates did not differ at other current levels. When morphine was withheld from slices from morphine-treated mice, pyramidal cells fired at a significantly lower frequency than those in vehicle-treated mice when stimulated with 275-375 pA ( $p=0.007-0.02$; Cohen's $d=0.6-0.7$; Fig. $1 D$ ). Intrinsic membrane properties were compared using two-way ANOVA. An interaction between Tat and drug treatment was observed in the resting membrane potential $\left(F_{(1,72)}=37.99, p<0.05 ; \eta^{2}=\right.$ 0.07 ). Pairwise comparisons using the Bonferroni correction for multiple comparisons (significance at $p<0.008$ ) revealed a significantly more depolarized resting membrane potential in pyramidal cells of Tat - versus Tat + vehicletreated mice $(p=0.003$; Cohen's $d=1.2$; Fig. $1 H)$. Additionally, Tat-exposed pyramidal cells required a greater amount of current (rheobase) to reach their firing threshold $\left(F_{(1,72)}=7.70, p<0.05 ; \eta^{2}=0.10 ;\right.$ Fig. $\left.1 /\right)$ and needed more current to attain their half-maximum firing frequency $\left(\mathrm{I}_{50} \%\right)$, regardless of whether morphine was present $\left(F_{(1,72)}=6.58, p<0.05 ; \eta^{2}=0.73\right)$ or withheld $\left(F_{(1,72)}=\right.$
4.95, $p<0.05 ; \eta^{2}=0.06$; Fig. 2). No significant effects were observed on the firing threshold of CA1 pyramidal cells (Fig. 1J). As in the previous comparison, neither the resistance nor capacitance were significantly affected by Tat and/or withholding morphine during the recordings (Table 1).

\section{Morphine and Tat exposure alter the density and morphology of pyramidal cell dendritic spines within specific hippocampal layers in CA1}

Distinct subsets of interneurons that project to specific pyramidal cell dendritic subdomains in discrete hippocampal layers (Pelkey et al., 2017) are a key determinant in the inhibitory-excitatory balance in CA1 (Bourne and Harris, 2011; Hiratani and Fukai, 2017). Tat perturbs distinct subsets of CA1 interneurons (Marks et al., 2016), selectively depletes Syt2-immunoreactive fibers in the SR, and suppresses LTP (Fitting et al., 2013), which were predicted to alter spine density along specific dendritic subdomains (Fig. 3). The morphologic effects of Tat on CA1 pyramidal cells were previously analyzed as whole cells or larger segments without consideration to these laminar divisions (Fitting et al., 2013). To better assess the regional variations within CA1 dendritic structure, the neurons used in the electrophysiological analyses were filled with biocytin (Fig. 3A) and analyzed morphologically with respect to CA1 laminae ( $n=10-12$; Fig. $3 B-J)$.

The effects of Tat and morphine on the density of dendritic spines differed in each CA1 layer. In the continued presence of morphine, there was a main effect of morphine on spine density in the SO $\left(F_{(1,41)}=8.402, p<0.05\right.$; $\left.\eta^{2}=0.17\right)$, where cells from morphine-treated mice had fewer spines per $10 \mu \mathrm{m}$ segment $(p=0.007$; Fig. 3/). Spine density in the SR was not affected by either morphine or Tat (Fig. 3/). Spine density in the SL-M was unaffected by Tat; however, in morphine-replete pyramidal cells, there

continued

steps in pyramidal cells from Tat+ mice had lower firing rates than those from Tat- mice. $\boldsymbol{E}$, Resting membrane potential $\left(\mathrm{V}_{\mathrm{R}}\right)$ showed significant interactions when exposed to Tat or morphine. Tat+ neurons were significantly more depolarized at rest, while morphine treatment appeared to negate the effects of Tat. $\boldsymbol{F}$, While no significant effects were noted in rheobase, there was a trend $(p=0.06)$ for pyramidal cells from Tat + mice to require a greater amount of current to reach a threshold for firing compared with cells from Tat- mice. $\boldsymbol{G}$, The threshold for firing $(\mathrm{mV})$ is significantly reduced in cells from morphine-treated mice. $\boldsymbol{H}$, There was a significant interaction between Tat and morphine on resting membrane potential $\left(V_{R}\right)$, which resulted from greater depolarized membrane potentials in vehicle-treated Tat + mice. $I$, Tat significantly increased rheobase, regardless of prior morphine treatment during the recording of morphine-withheld slices. Pyramidal cells from Tat + mice required a greater amount of current ( $\mathrm{pA}$ ) to reach the threshold potential for firing than Tat- mice, although the firing threshold $(\mathrm{mV})$ of CA1 pyramidal cells was unaffected by Tat or morphine exposure $(\boldsymbol{J})$. Patched cells were stimulated with $500-\mathrm{ms}$ current pulses starting at $-100 \mathrm{pA}$ and escalating to $400 \mathrm{pA}$ in $25-\mathrm{pA}$ steps; * indicates significant difference between Tat- and Tat + tissues; ${ }^{\dagger}$ indicates a significant decline in firing rates in slices from Tat + , but not Tat - , mice previously exposed to morphine when morphine was withheld $(p<0.05)$. 

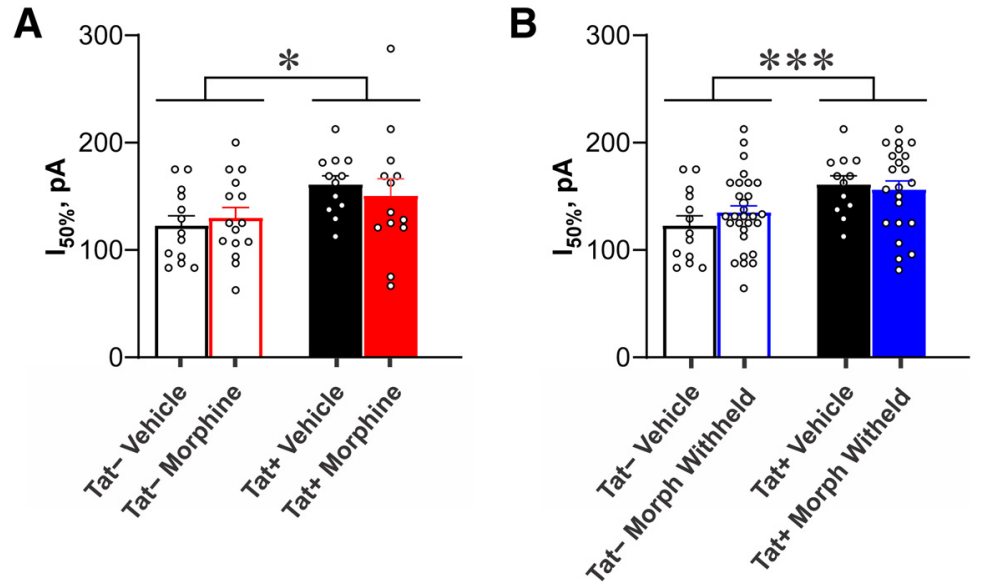

Figure 2. The amount of current injected to maintain $I_{50} \%$, or $50 \%$ of the maximal firing rate observed across all current steps $(-100-400 \mathrm{pA}$ in $25-\mathrm{pA}$ steps) per cell (see Fig. 1A-D), is significantly increased in CA1 pyramidal cells of Tat + compared with Tatmice (main effect; $F_{(1,72)}=7.70, p<0.05$ ), regardless of whether morphine is present $(\boldsymbol{A})$ or withheld $(\boldsymbol{B})$ during the recording. These data indicate that one week of Tat exposure is sufficient to fundamentally alter CA1 pyramidal cell excitability; * indicates a significant difference between pyramidal cells from Tat- and Tat + mice $(p<0.05)$; individual data points, representing individual cells, are shown by open circles.

was a trend for Tat to interact with morphine to increase SL-M spine density $\left(F_{(1,38)}=3.47, p=0.07 ; \eta^{2}=0.07\right)$. Consequently, the effects of morphine on SL-M spine density were examined further in pyramidal cells in Tatand Tat + mice separately. Significant effects were observed in Tat - cells $\left(t_{(19)}=2.823, p<0.05 ; \eta^{2}=0.29\right)$, but not Tat + cells. Morphine-treated pyramidal cells in Tatmice had fewer SL-M spines than in vehicle-treated Tatmice $(p=0.015$; Fig. $3 K)$. Furthermore, there were differences in the density of dendritic spines depending on whether morphine was present or absent during the recordings. When morphine was withheld during the recording period, a trend toward reductions in spine density was evident in the SO $\left(F_{(1,38)}=3.64, p=0.064 ; \eta^{2}=0.08\right.$; Fig. $3 L)$ and $\operatorname{SR~}\left(F_{(1,38)}=3.55, p=0.067 ; \eta^{2}=0.08\right.$; Fig. $3 M)$, but not the SL-M, of slices from Tat + mice that had previously been exposed to morphine.

The morphology of dendritic spines transforms from more transient, immature thin/filopodial spines to mature mushroom spines as they become stable (Harris et al., 1992; Ochs et al., 2015; Schier et al., 2017). Representative images of dendritic spines within the major CA1 strata are shown in Figure $4 A-C$. To unambiguously categorize dendritic spines of a morphologic type, about one half of spines with indefinite or intermediate morphology were excluded; thereby reducing the overall estimates of spine density compared with measurements in which all spines are counted (Figs. 4, 5). Tat exposure reduced intermediate, stubby dendritic spine subtypes in the SO $\left(F_{(1,41)}=6.96, p=0.012 ; \eta^{2}=\right.$ 0.14 ; Fig. $4 E)$ and $\operatorname{SR}\left(F_{(1,41)}=6.13 ; \eta^{2}=0.06 ; p=0.018\right)$ of morphine-replete, as well as the SO $\left(F_{(1,40)}=10.77 ; \eta^{2}=\right.$ $0.21 ; p=0.002$; Fig. 5) and SR $\left(F_{(1,39)}=4.74 ; \eta^{2}=0.11\right.$; $p=0.036$; Fig. 5) of pyramidal cells in which morphine was withheld (Fig. 5). There was a significant increase in the percentage of indefinite or intermediate spines in morphine-replete pyramidal cells in the SO $\left(F_{(1,37)}=4.72, p=0.0363\right.$; $\eta^{2}=0.10$; Fig. 4E). Within the SR, the proportion of indefinite or intermediate spines were increased by Tat exposure in morphine-replete $\left(F_{(1,38)}=8.11, p=0.0071 ; \eta^{2}=0.16\right.$; Fig. $4 E$ ) and morphine withheld $\left(F_{(1,38)}=22.85, p<0.0001 ; \eta^{2}=\right.$ 0.38 ; Fig. 5) pyramidal cells. Within the SL-M, withholding morphine increased the density of stubby spines compared with vehicle, regardless of Tat exposure $\left(F_{(1,36)}=5.92 ; \eta^{2}=\right.$ $0.02 ; p=0.020$; Fig. 5). Tat-exposed pyramidal cells had reduced mushroom type spines in the SR, regardless of treatment in comparisons in which morphine was withheld $\left(F_{(1,39)}=7.37 ; \eta^{2}=0.16 ; p=0.010 ;\right.$ Fig. 5). Continuous morphine treatment decreased thin/filopodial spines in the SR $\left(F_{(1,41)}=6.96 ; \eta^{2}=0.14 ; p=0.012 ;\right.$ Fig. $\left.4 E\right)$ and SL-M $\left(F_{(1,37)}=4.50 ; \eta^{2}=0.11 ; p=0.0406 ;\right.$ Fig. $\left.4 E\right)$. Withholding morphine reduced SR thin/filopodial spine densities regardless of genotype $\left(F_{(1,39)}=5.78 ; \eta^{2}=0.12 ; p=0.021\right.$; Fig. 5). By contrast, withholding morphine interacted to significantly alter SL-M thin/filopodial spine density only in Tat-exposed cells $\left(F_{(1,36)}=4.32 ; \eta^{2}=0.10 ; p=0.045\right.$; Fig. 5), where withholding morphine in Tat - mice, but not Tat+ mice, significantly increased the proportion of thin/filopodial spines $(p=0.029$; Cohen's $d=0.9)$.

\section{Morphine and Tat exposure did not alter the density of inhibitory postsynaptic puncta}

To assess whether Tat-dependent reductions in specific subsets of interneurons (Marks et al., 2016) and Syt2expressing presynaptic fibers in the SR in CA1 (Fitting et al., 2013) resulted in the loss of inhibitory postsynaptic terminals, the number of puncta was quantified along the aspinous portions of the basilar and apical dendrites of pyramidal cells as they emerged from the soma. This region of both the basilar and apical portions of the dendrite is known to have the highest percentage of inhibitory contacts onto pyramidal cells (Megías et al., 2001). The results show no significant interactions between or main effects of either Tat or morphine on the number of inhibitory puncta within the basilar or apical dendritic shafts in the perisomatic region (Fig. 6). 

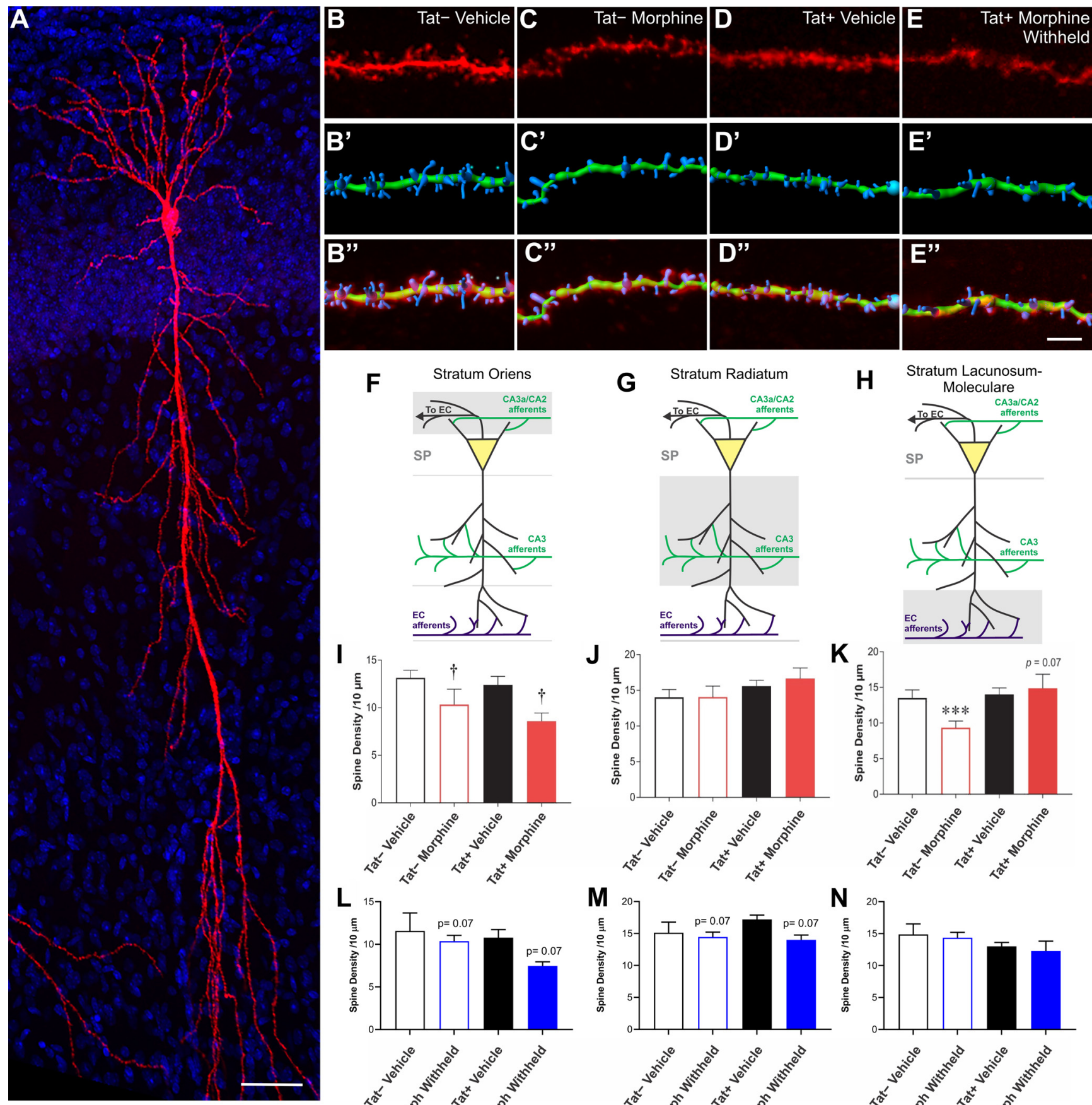

$\mathbf{F}$
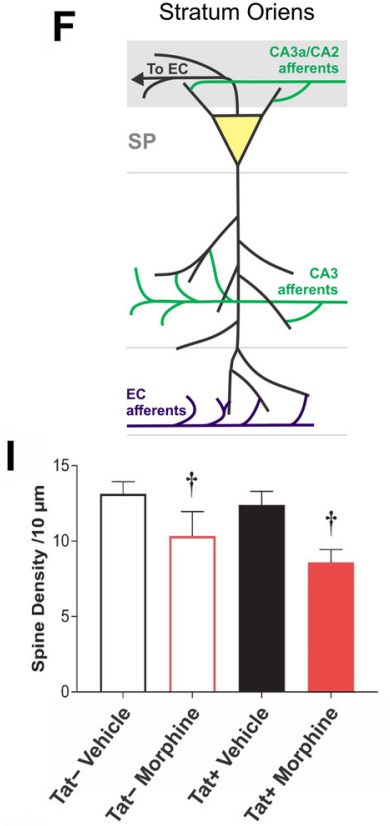

L

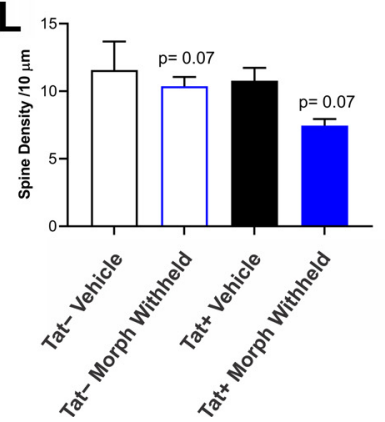

G

Stratum Radiatum

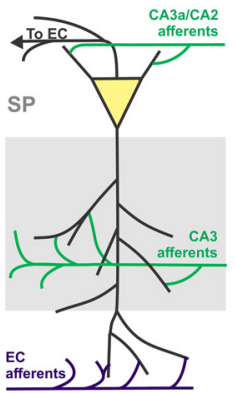

$\underset{\text { afferents) }}{E C} \lambda$

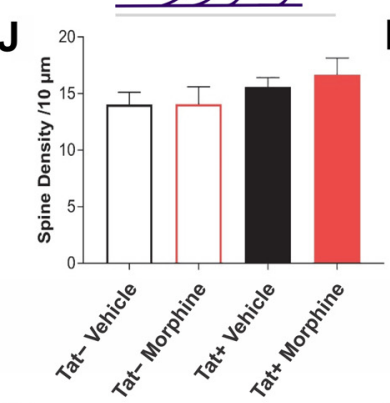

M
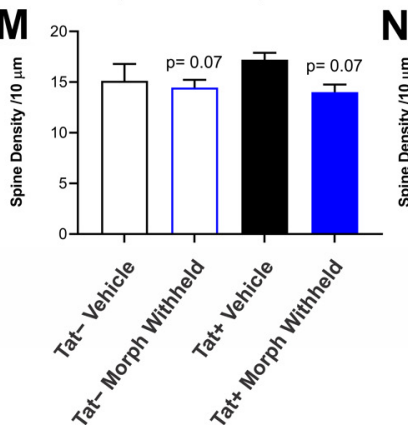

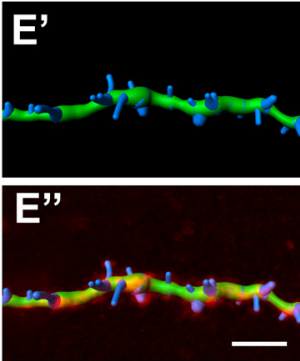

H Stratum Lacunosum-

Moleculare
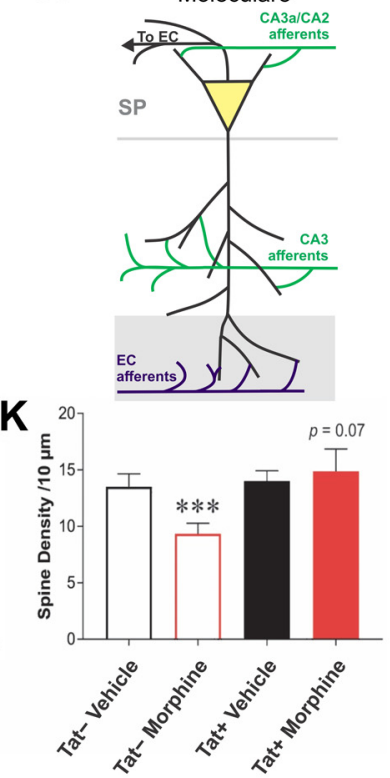

N

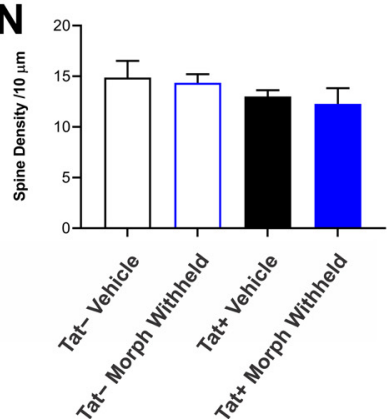

Figure 3. Effects of Tat and morphine on spine density along specific pyramidal cell dendritic segments within the SO, SR, and SL$\mathrm{M}$ of hippocampal area CA1. A, Reconstructed Z-stack image of a representative biocytin-filled pyramidal cell within hippocampal area CA1 from a vehicle-treated Tat- mouse. Scale bar: $50 \mu \mathrm{m}$. B-E, Sample pyramidal cell dendritic segments and 3D reconstructions from the SO of control, morphine, Tat, and morphine plus Tat-exposed mice. The top image is the raw image file (B-E). The image below shows a representative 3D-reconstructed dendritic segment (green) and its associated spines (blue; $\boldsymbol{B}^{\prime}-\boldsymbol{E}^{\prime}$ ). The final image superimposes the raw image of the dendrite and its spines with the 3D reconstruction of the same dendritic segment and spines $\left(\boldsymbol{B}\right.$ '- $\left.-\boldsymbol{E}^{\prime \prime}\right)$. Scale bar: $10 \mu \mathrm{M}$. $\boldsymbol{F}, \boldsymbol{I}, \boldsymbol{L}$, Illustration of the location of pyramidal cell dendritic portion sampled is shaded in gray $(\boldsymbol{F})$ and mean spine densities \pm the SEM within the SO $(\boldsymbol{I}, \boldsymbol{L})$. $\boldsymbol{I}$, There was a main effect of sustained morphine exposure in vivo and during recordings to reduce overall SO spine density $\left({ }^{\dagger} p=0.007\right)$. $L$, Spine losses were no longer significant after morphine was withheld, suggesting morphine-dependent spine losses are plastic and reversible. $\mathbf{G}, \boldsymbol{J}, \boldsymbol{M}$, Illustration of the location of pyramidal cell dendritic portion sampled is shaded in gray $(\boldsymbol{G})$ and mean spine densities \pm the SEM within the SR $(\boldsymbol{J}, \boldsymbol{M})$. $\boldsymbol{J}$, No differences in spine density in SR dendrites were observed in Tat- or Tat + in the absence or presence of sustained exposure to morphine in vivo and during recordings ex vivo. $\boldsymbol{M}$, By contrast, withholding morphine tended to induce spine losses. $\boldsymbol{H}, \boldsymbol{K}, \boldsymbol{N}$, Illustration of the location 

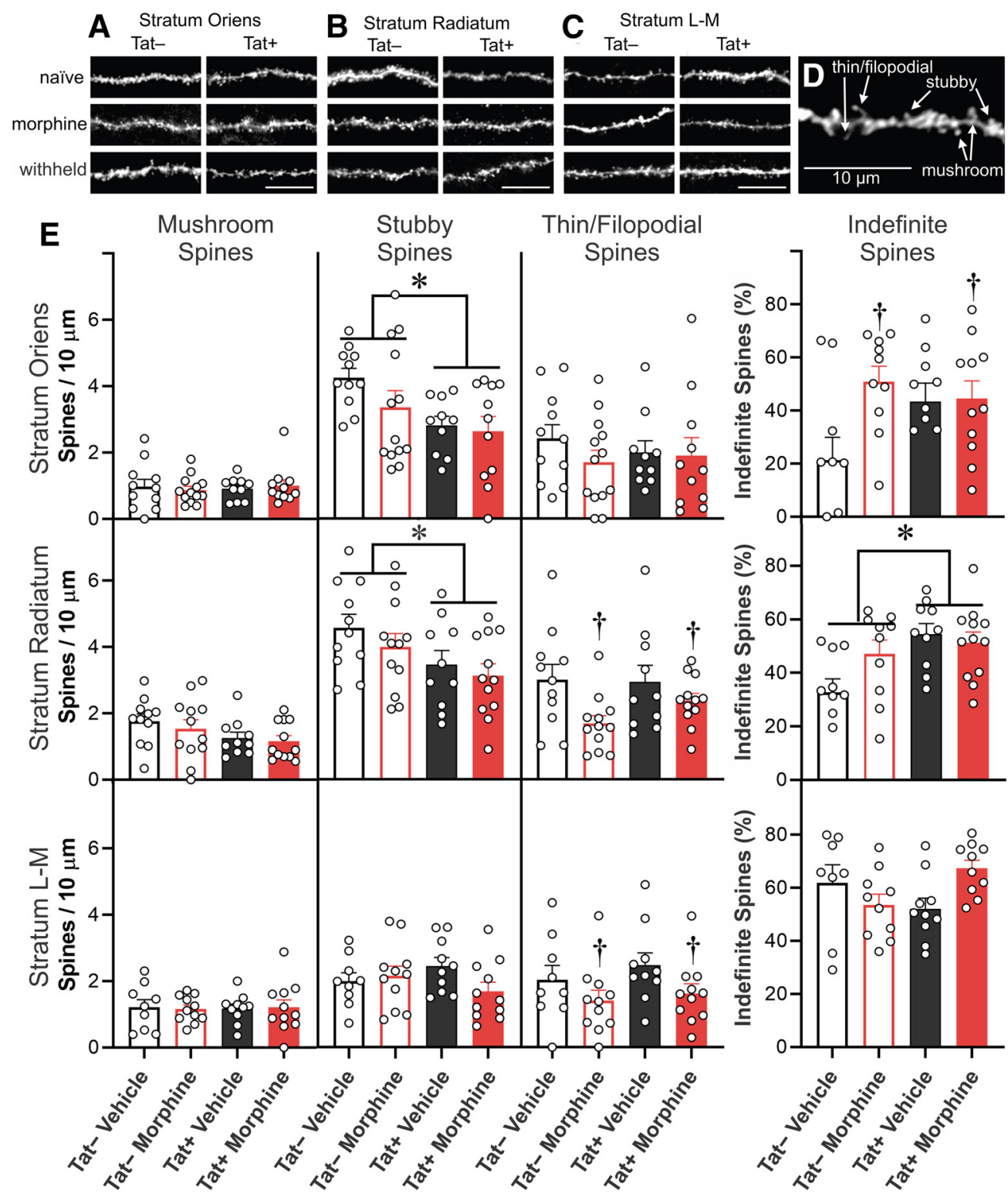

Figure 4. $\boldsymbol{A}-\boldsymbol{E}$, Spine subtype analyses of CA1 pyramidal neurons cells from Tat- or Tat + mice. Mice were treated with vehicle control or morphine $(25 \mathrm{mg})$ time-release implants; during electrophysiological recordings, morphine was present (500 nM, "morphine"). Spine subtypes were analyzed independently in SO (A), SR (B), and SL-M (C) according to their morphological classification as "mushroom," "Stubby," or "thin/filopodial" type spines $(\boldsymbol{D})$. Dendritic spines of an indefinite or intermediate morphology were analyzed separately, thereby reducing the overall estimates of spine density compared with measurements in which all spines are counted (Fig. 3). Scale bars: $10 \mu \mathrm{m}$. (E) Tat exposure reduced intermediate, stubby dendritic spine subtypes in the SO and SR of morphine-replete pyramidal cells. There was a significant increase in the percentage of indefinite or intermediate spines in pyramidal cells in the SO with sustained morphine exposure. Within the SR, the proportion of indefinite or intermediate spines were increased in Tat-exposed pyramidal cells continuously exposed to morphine. Continuous morphine treatment decreased thin/filopodial spines in the SR and SL-M, while increasing SO indefinite spines in Tat exposed cells; * indicates a significant difference between Tatand Tat + tissues; ${ }^{\dagger}$ indicates a significant difference between morphine-replete and vehicle-treated tissues, $p<0.05$.

continued

of pyramidal cell dendritic portion sampled is shaded in gray $(\boldsymbol{H})$ and mean spine densities \pm the SEM within the SL-M $(\boldsymbol{K}, \boldsymbol{N})$. $\boldsymbol{K}$, Morphine caused a reduction in SL-M dendritic spine density in pyramidal cells from Tat-, but not Tat + , mice $\left({ }^{\star \star *} p<0.05\right)$. In fact, there was a trend for Tat to reverse morphine-dependent reductions in dendritic spine density with sustained morphine exposure ex vivo, albeit not significantly $(p=0.07)$, suggesting that Tat and morphine uniquely interact to increase spine numbers on the SL-M (G). $\boldsymbol{N}$, By contrast, withholding morphine from ex vivo slices during recordings negated any changes in spine density seen when morphine is present ( $N$ vs $\boldsymbol{K}$ ), suggesting the changes in spine density caused by morphine are highly plastic and modifiable. 


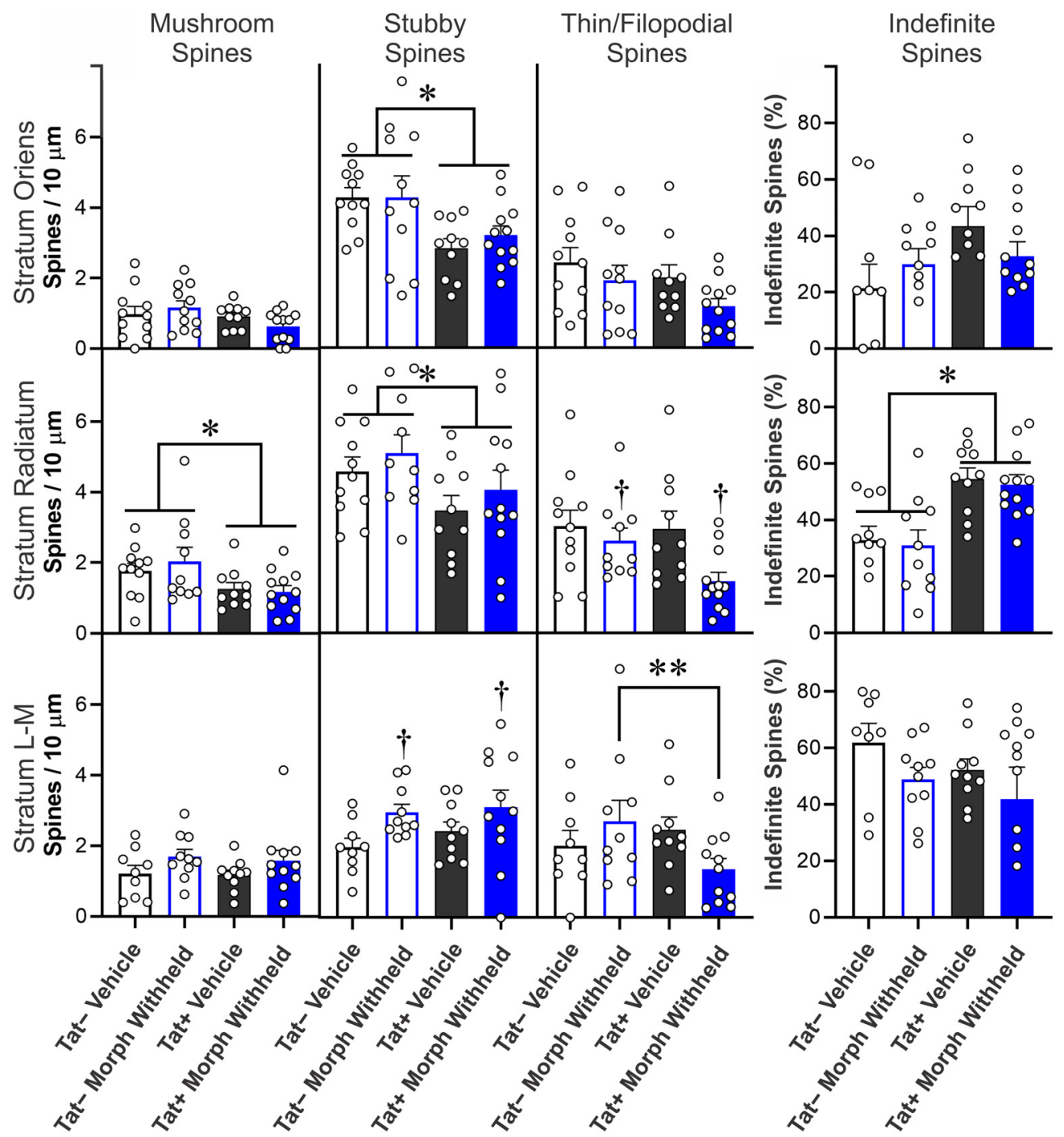

Figure 5. Spine subtype analyses of CA1 pyramidal neurons cells from Tat- or Tat + mice. Mice previously treated with vehicle control or morphine $(25 \mathrm{mg})$ time-release implants in which morphine was withheld ( $0 \mathrm{~nm}$, "withheld") during electrophysiological recordings. Spine subtypes (mushroom, stubby, or thin/filopodial) were analyzed individually. Dendritic spines of an indefinite or intermediate morphology were analyzed separately, thereby reducing the overall estimates of spine density compared with measurements in which all spines are counted (Fig. 3). Tat exposure reduced intermediate, stubby dendritic spine subtypes in the SO and SR of pyramidal cells in which morphine was withheld. Within the SR, withholding morphine increased the proportion of indefinite spines with concurrent Tat exposure. In the SL-M, morphine treatment increased the density of stubby spines when morphine was withheld, regardless of Tat exposure. Tat exposure reduced mushroom type spines in the SR regardless of treatment. Withholding morphine reduced SR thin/filopodial spine densities regardless of genotype. By contrast, withholding morphine interacted to significantly alter SL-M thin/filopodial spine density in Tat-exposed pyramidal cells, while withholding morphine specifically increased the proportion of thin/filopodial spines in Tat- mice; * indicates a significant difference between Tat- and Tat+ tissues; ${ }^{\dagger}$ indicates significant a difference between vehicle-treated and morphine-withheld tissues, $p<0.05$.

\section{CA1 volume was unaffected by morphine and Tat exposure, while Tat increased the volume of CA3}

Stereology was performed to assure any changes in dendritic spine density/morphology in CA1 were not distorted by alterations in the volume in this region of the hippocampus (e.g., through gliosis, vascular leakiness (Leibrand et al., 2019); or possible disruptions in glymphatic drainage). No significant influence of morphine or Tat genotype was observed on the $V_{V} s$ of CA1, CA2, or the dentate gyrus. By contrast, the volume of CA3 was significantly greater among Tat + , compared with Tat-, mice regardless of whether morphine was administered $\left(F_{(1,20)}=6.350 ; \eta^{2}=0.20 ; p=0.02 ;\right.$ Fig. 7 ; Table 2$)$.

\section{Morphine and Tat exposure impaired Barnes maze performance}

Pyramidal neuron firing within the CA1 area of the hippocampus plays an important role in spatial memory (Gothard et al., 1996). Tat- and Tat+ mice, implanted with vehicle-containing or morphine-containing pellets were assessed on the Barnes maze across $4 \mathrm{~d}$ and a 

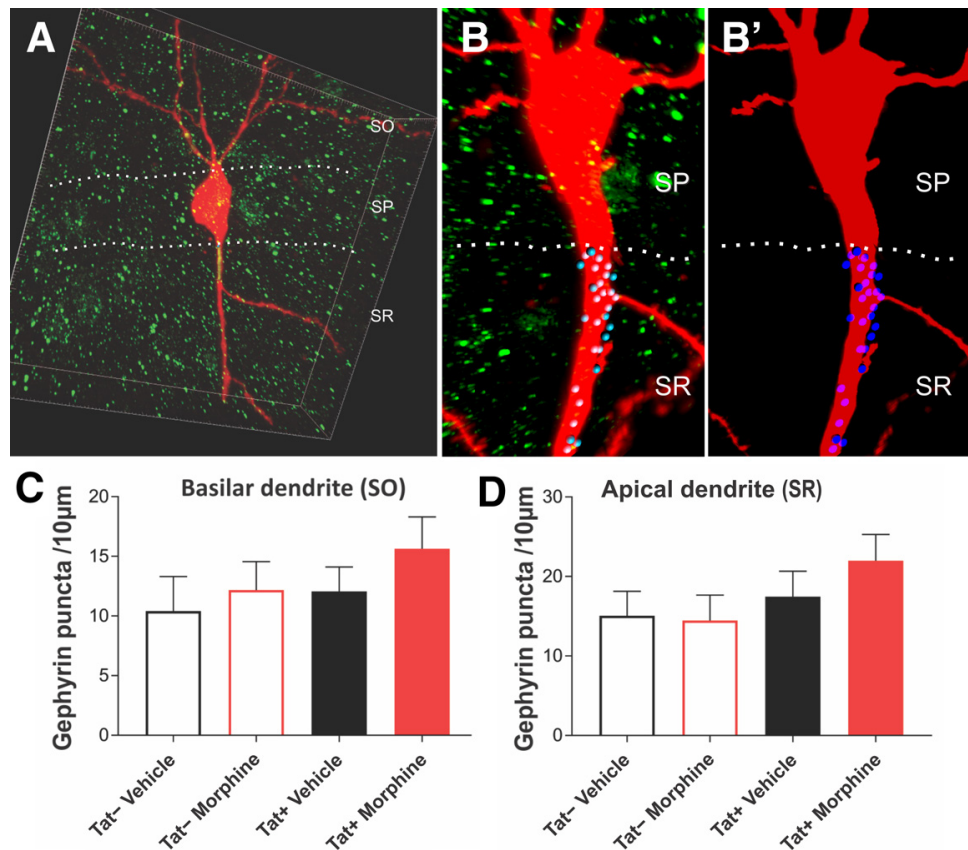

Figure 6. Assessment of inhibitory, postsynaptic gephyrin puncta within the aspinous, proximal dendrites of CA1 pyramidal cells. Biocytin-filled pyramidal cells labeled with an Alexa Fluor 594-conjugated streptavidin probe (red) and gephyrin puncta (green) were analyzed. $\boldsymbol{A}, \boldsymbol{B}, \boldsymbol{B}^{\prime}$, A third channel (blue, with darker blue puncta are in front of the dendrite; lighter blue puncta are behind the dendrite; $\left.\boldsymbol{B}, \boldsymbol{B}^{\prime}\right)$, only identifying the gephyrin puncta that were adjacent or overlapped with the aspinous portions of the basilar $(\boldsymbol{C})$ or perisomatic apical $(\boldsymbol{D})$ pyramidal cell dendrite, from 3D-reconstructed images was quantified. No changes in the number of gephyrin-immunoreactive puncta were observed. Box Dimensions in A: $100 \times 100 \times 20 \mu \mathrm{m}$. Data represent the mean number of gephyrinpositive puncta \pm SEM per $10-\mu \mathrm{m}$ length of dendrite.

reversal probe trial (Fig. 8A). Compared with those implanted with vehicle pellets, mice implanted with morphine pellets took significantly longer to find the escape hole, regardless of Tat genotype $\left(F_{(1,216)}=15.15\right.$, $p<0.05 ; \eta^{2}=0.22$; Fig. 8B). Genotype significantly interacted with the day of testing $\left(F_{(4,216)}=3.60, p<0.05 ; \eta^{2}=\right.$ $0.004)$ such that Tat- mice demonstrated a significantly lower latency to escape on every day compared with their initial performance on day $1(p<0.001-0.001$; Cohen's $d=0.7-1.1$; Fig. $8 B$ ). In contrast, Tat + mice did not outperform their initial day 1 performance until days 3 and 4 $(p<0.001$; Cohen's $d=0.6-0.7$; Fig. 8B). Both strains of mice demonstrated a significantly increased latency to escape on the reversal probe trial compared with their day 4 performance $(p<0.0001-0.003$; Cohen's $d=0.4-$ 1.0; Fig. 8B).

Similarly, there was a significant three-way interaction for the proportion of time spent in the correct quadrant of the Barnes maze $\left(F_{(4,216)}=3.96, p<0.05 ; \eta^{2}=0.05\right)$, such that Tat + mice spent less time in the correct quadrant than did Tat- controls on days 3 and four of testing $(p=0.02-0.045$; Cohen's $d=0.9$; Fig. $8 C$ ). Morphine did not affect the percent of time spent in the correct quadrant on days 1-4; however, on the day of reversal testing, morphine significantly increased the proportion of time spent in the correct quadrant among Tat- mice $(p=0.01$; Cohen's $d=0.9)$, while tending to decrease it among Tat + mice ( $p=0.056$; Cohen's $d=0.8$; Fig. $8 C$ ).
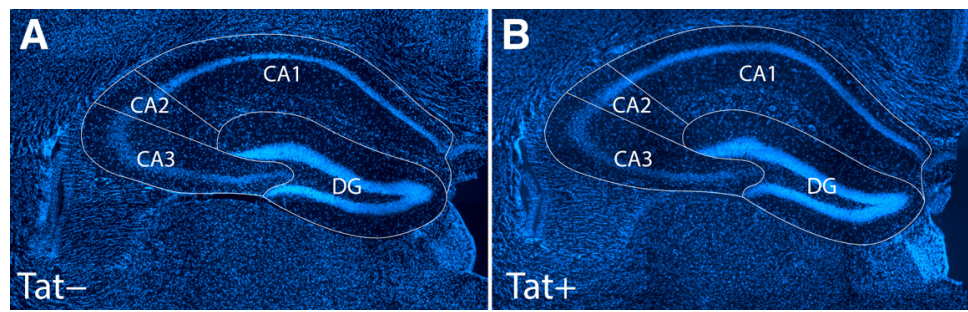

Figure 7. $\boldsymbol{A}, \boldsymbol{B}$, There was no effect of Tat or morphine exposure on the $\mathrm{V}_{\mathrm{V}}$ of hippocampal areas $\mathrm{CA} 1$, CA2, or the dentate gyrus (DG); however, the volume of CA3 was significantly increased by Tat induction regardless of morphine exposure (see Table 1). Importantly, the measurements of dendritic spine density (Figs. 4, 5) were not distorted by morphine-dependent or Tat-dependent alterations in the volume of hippocampal area CA1. Images show representative Hoechst 33342-stained, 40- $\mu$ m-thick coronal sections of the hippocampus from Tat $-(\boldsymbol{A})$ and Tat $+(\boldsymbol{B})$ mice used for stereology. 
Table 2: Stereological analyses of hippocampal volume

\begin{tabular}{lllll}
\hline & Tat- & Tat- & Tat+ & Tat+ \\
Vehicle & Morphine $(25 \mathrm{mg})$ & Vehicle & Morphine (25 mg) \\
\hline CA1 & $44.35 \pm 2.48 \%$ & $43.97 \pm 0.72 \%$ & $40.19 \pm 3.48 \%$ & $46.13 \pm 3.18 \%$ \\
CA2 & $5.00 \pm 0.71 \%$ & $5.03 \pm 0.68 \%$ & $4.70 \pm 0.65 \%$ & $5.21 \pm 1.07 \%$ \\
CA3 & $26.71 \pm 1.93 \%$ & $26.58 \pm 1.53 \%$ & $35.92 \pm 2.26 \% *$ & $28.91 \pm 2.88 \% *$ \\
DG & $26.94 \pm 1.45 \%$ & $24.42 \pm 1.24 \%$ & $28.31 \pm 2.19 \%$ & $28.07 \pm 2.87 \%$ \\
\hline
\end{tabular}

No significant alterations in total hippocampal volume fraction $\left(V_{v}\right)$ for CA1, CA2, or the dentate gyrus (DG) were found in male Tat transgenic mice $(n=5-8)$ following two weeks of Dox and 5 d subcutaneous vehicle-containing or morphine $(25 \mathrm{mg})$-containing time-release implants. A significant increase in hippocampal area CA3 volume was detected for Tat + mice; ${ }^{*}$ indicates a significant difference between Tat - and Tat + tissues, $p<0.05$ and also indicated in bold text.

The number of errors made $\left(F_{(1,212)}=4.90, p<0.05\right.$ $\eta^{2}=0.08$; Fig. 8D) and distance traveled $\left(F_{(1,216)}=9.10\right.$, $p<0.05 ; \eta^{2}=0.14$; Fig. $8 E$ ) in the Barnes maze were also significantly influenced by Tat and morphine. Tat + mice administered morphine made more errors $(p=0.02$; Cohen's $d=0.4$; Fig. 8D) and traveled greater distances on day $1(p=0.02$; Cohen's $d=0.4$; Fig. $8 E)$ than did their vehicle-exposed counterparts. Conversely, morphine decreased the distance traveled by Tat- controls compared with their vehicle-exposed counterparts $(p=0.04$; Cohen's $d=0.4$; Fig. $8 E$ ). After day 1 , all groups made fewer errors $\left(F_{(4,212)}=22.16, p<0.05 ; \eta^{2}=0.28\right.$; Fig. $8 D)$ and traveled less distance $\left(F_{(4,216)}=21.91\right.$, $p<0.05 ; \eta^{2}=0.28$; Fig. $8 E$ ) on subsequent testing days $(p<0.0001-0.006$; Cohen's $d=0.1-1.1)$. On the reversal probe trial, all groups made more errors $(p<0.0001$; Cohen's $d=1.2)$ and traveled a greater distance $(p<$ 0.0001 ; Cohen's $d=1.1$ ) compared with their day 4 performance. Irrespective of genotype, there was a significant main effect for morphine to reduce the speed at which mice traveled $\left(F_{(1,216)}=6.30, p<0.05 ; \eta^{2}=0.10\right.$; Fig. $8 F$ ). The speed of travel for Tat + animals was notably greater on the reversal probe trial compared with any other day of testing $(p<0.0001-0.03$; Cohen's $d=0.3-$ 0.5; Fig. 8F).

\section{Discussion}

The interactive effects of morphine and HIV-1 Tat were assessed on the intrinsic and evoked activity of hippocampal neurons. Changes in pyramidal cell structure and function were compared with subsequent behavioral deficits associated with neuroHIV and OUD. Morphine was delivered via subcutaneously implanted pellets, which are widely used to administer sustained, high circulating concentrations in rodents. The 25-mg implants deliver clinically relevant plasma/tissue levels of morphine (Ghazi-Khansari et al., 2006), inducing tolerance (Chefer and Shippenberg, 2009) and physical dependence within $3 \mathrm{~d}$ in C57BL/6 mice (Bogulavsky et al., 2009). Unlike the numerous opioid and HIV interactions in the striatum (Fitting et al., 2020), Tat and morphine appear to act largely independently to disrupt hippocampal neuronal function. However, withholding morphine from morphinedependent tissues during ex vivo recordings revealed significant, albeit subtle, opioid-HIV interactions with respect to pyramidal excitability and dendritic plasticity at higher stimulating currents. Additional studies are required to determine the extent to which these responses reveal underlying neuroadaptive changes in response to sustained morphine exposure, and the extent to which the pharmacokinetics of opioid exposure mediate pathophysiological opioid and HIV interactions.

Prior observations of selective reductions in GABAergic interneuronal subpopulations (Marks et al., 2016) and reduced GABAergic SR afferents (Fitting et al., 2013) infer that Tat should, on net balance, increase neuronal excitability, as has been observed in vitro (Magnuson et al., 1995). However, Tat exerted the opposite effect at lower current intensities in the present study. This unanticipated decrease in CA1 pyramidal cell firing rates might result from (1) Tat-induced (and presumably transient) excitotoxic increases in GABA release from vulnerable interneurons; (2) compensatory changes in GABAergic interneuronal networks/network oscillations (Fitting et al., 2013, 2020; Marks et al., 2016); (3) Tat-mediated increases in gephyrin, a $\mathrm{GABA}_{\mathrm{A}}$ receptor organizer (Fitting et al., 2013; Choii and Ko, 2015); and/or (4) altered connectivity from synaptodendritic injury associated with chronic, low-level Tat exposure (Dickens et al., 2017). Tat not only disrupts the organization of excitatory and inhibitory connections impacting pyramidal cells in CA1 (Marks et al., 2016) and elsewhere in the hippocampus (BruceKeller et al., 2003; Maragos et al., 2003), it can also adjust inhibitory and excitatory activity through compensatory homeostatic alterations in synaptic scaling (Hargus and Thayer, 2013; Green et al., 2019). Notably, our findings identify more robust Tat-dependent deficits on CA1 pyramidal cell excitability than seen in an alternate HIV-1 Tat transgenic mouse model (Cirino et al., 2020), which may result from more prolonged (14-d) Tat exposure.

\section{Tat alters long-term circuit neuroadaptations to morphine}

In mice maintained on morphine, pyramidal cell responsiveness differed depending on whether morphine was present or withheld during the recordings. Sustained morphine exposure during the recording reduced the firing threshold but did not impact overall firing rates. By contrast, when morphine was withheld during recording, pyramidal cells had significantly lower firing rates at high stimulating currents without a commensurate change in firing threshold. Since acute morphine exposure typically increases CA1 pyramidal cell firing by inhibiting presynaptic afferents from MOR-expressing inhibitory interneurons (Siggins and Zieglgänsberger, 1981), and can hyperpolarize specific subsets of interneurons (Drake and Milner, 2002; McQuiston and Saggau, 2003; McQuiston, 2008), 
A
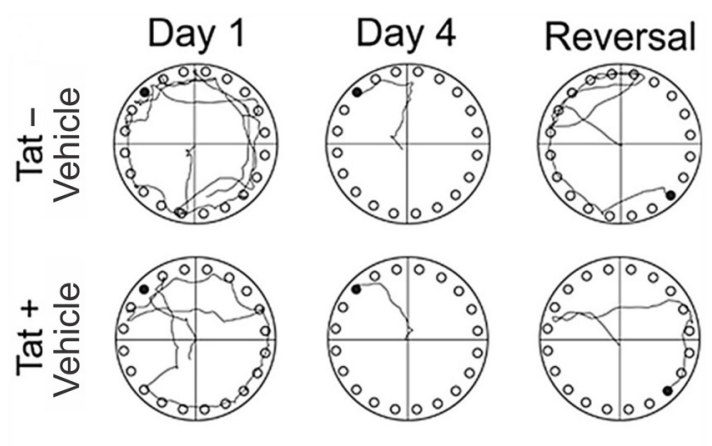

$+\frac{\stackrel{0}{\frac{1}{c}}}{+\frac{0}{\frac{0}{2}}}$
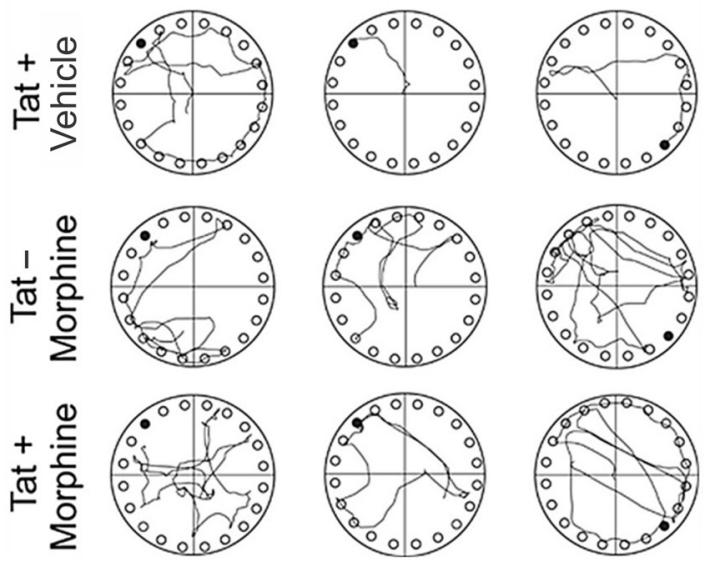

D
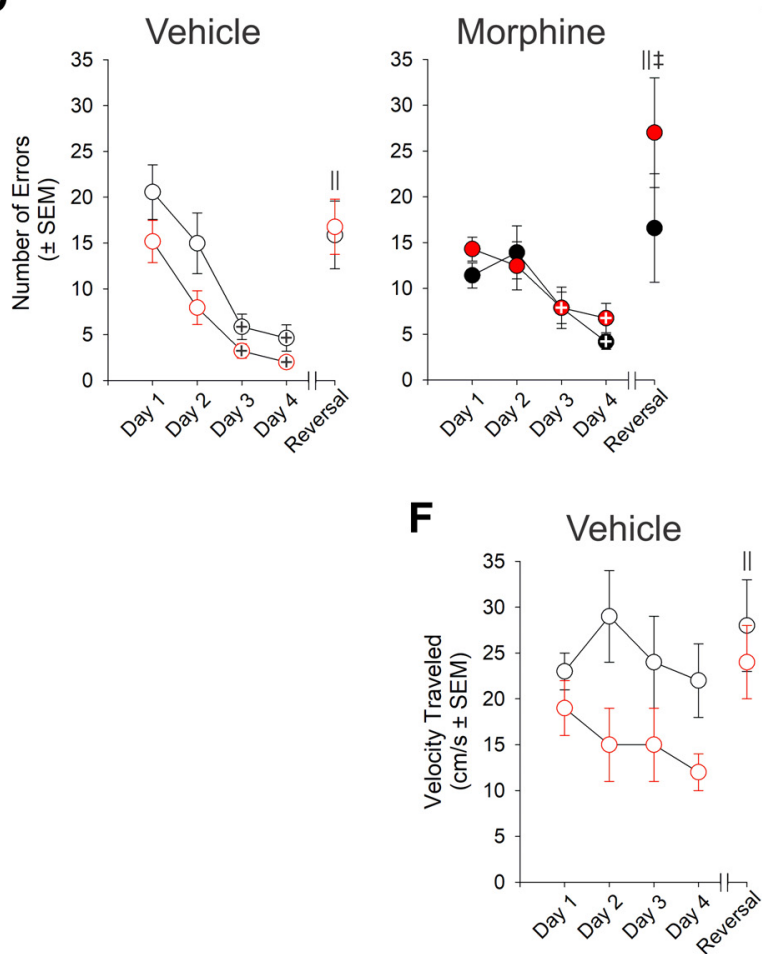

B
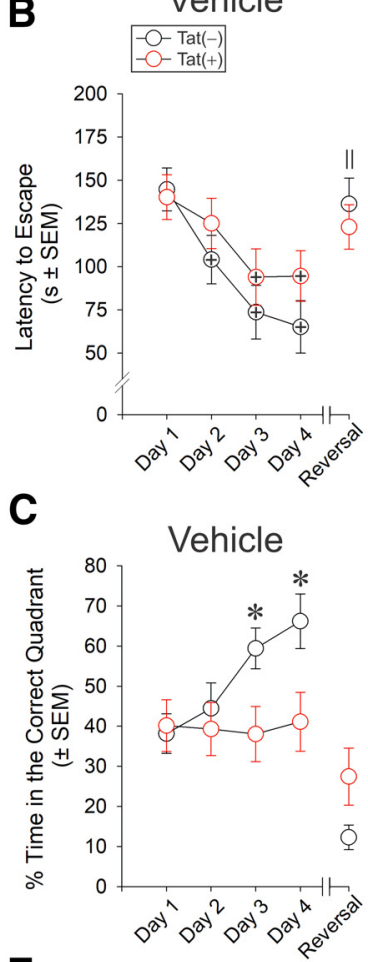

E
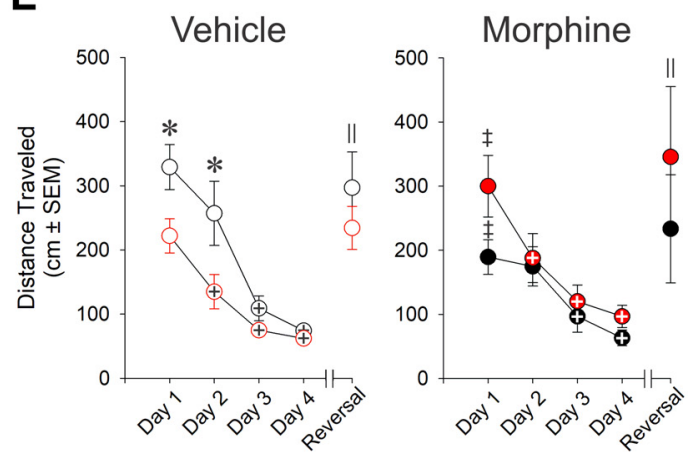

Morphine
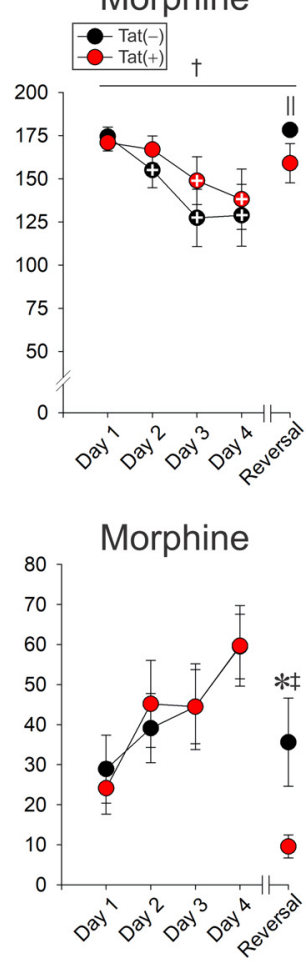

Morphine

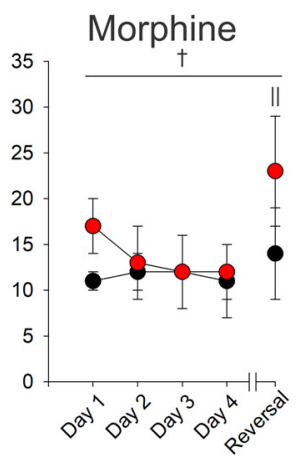

Figure 8. Effects of morphine and HIV-1 Tat exposure on spatial learning. $\boldsymbol{A}$, Representative paths traveled by vehicle-exposed or morphine-exposed Tat- and Tat + mice ( $n=12-17 /$ group) on the Barnes maze test (the filled black circle indicates the escape goal; open circles indicate decoy escape locations). $\boldsymbol{B}$, Tat- mice showed a significant decrease in the latency (s) during $4 \mathrm{~d}$ of training trials to find the escape hole compared with Tat+ mice, while morphine increased the latency regardless of genotype. $\boldsymbol{C}$, Tat- mice spent a greater proportion of time in the correct quadrant than Tat + mice. Although morphine increased the proportion of time Tat + mice spent in the correct quadrant, morphine-treated mice spent significantly less time in the correct quadrant during the reversal probe trial. $\boldsymbol{D}$, Tat- and Tat + mice made fewer errors on days 3 and 4 . Morphine increased the errors made by Tat + mice on the reversal probe trials. $\boldsymbol{E}$, Tat + mice traveled shorter distances $(\mathrm{cm})$ on days 1 and 2 and reduced their daily travel significantly sooner than Tat- mice. On day 1, morphine increased the distance traveled by Tat+ mice, while reducing the distance traveled by 
continued

Tat- mice. $\boldsymbol{F}$, The velocity of travel $(\mathrm{cm} / \mathrm{s})$ was reduced by morphine exposure. ${ }^{\dagger}$ main effect for morphine differed from vehicle treatments; " reversal day performance significantly differs from day 4 performance; ${ }^{+}$indicates the group significantly differs from day 1 performance; * indicates the Tat - and respective Tat + groups differ significantly; ${ }^{*}$ indicates the morphine and respective vehicle-treated groups differ significantly, $p<0.05$.

changes in CA1 pyramidal cell excitability following sustained morphine exposure may result from neuroadaptation because of abnormal presynaptic inhibition, changes in ion channel composition or distribution, and/or altered microcircuitry. Abruptly withholding morphine's inhibitory effects from opioid-tolerant interneurons likely results in their transient overexcitation, excess presynaptic GABA release (Christie, 2008), and the suppression of pyramidal cell firing rates. When morphine was withheld from the slices taken from morphine-pelleted mice, significant reductions were seen in both (1) firing thresholds and (2) firing frequencies at high current amplitudes, although intrinsic resistance and capacitance measures were largely unchanged by Tat and morphine. Neuroadaptation seems to occur at multiple levels, since alterations in the number and morphologic type of dendritic spines along specific dendritic domains were also evident. Our findings are generally consistent with known circuit/ensemble-based effects of morphine on CA1 neuronal activity (Harrison et al., 2002; Liu et al., 2010; Farahmandfar et al., 2011a,b).

Tat additionally reduced intrinsic excitability, which is also seen with prolonged Tat applications (Francesconi et al., 2018). Analysis of contrasts assessing possible morphine and Tat interactions revealed that changes in membrane potential and rheobase were largely driven by Tat. Interestingly, more protracted exposure to Tat does not alter intrinsic membrane properties despite altered excitability (Francesconi et al., 2018), suggesting the network effects of Tat precede its direct effects on CA1 pyramidal cells. However, based on morphologic measures and past studies, Tat is likely affecting both the pyramidal cells and the interneuron network (Fitting et al., 2013; Marks et al., 2016; Francesconi et al., 2018).

\section{Deficiencies in dendritic spines are associated with the severity of HAND and decreased plasticity}

The development of HAND has been associated with HIV-1-induced synaptodendritic injury and culling (Ellis et al., 2007; McArthur et al., 2010; Saylor et al., 2016; Smail and Brew, 2018). Tat-induced reductions of spine density have been observed in the cortex, striatum, and hippocampus (Fitting et al., 2013; Hahn et al., 2015; Raybuck et al., 2017; Schier et al., 2017), while sustained morphine exposure is known to reduce the density of spines in CA1 pyramidal cells (Robinson et al., 2002; Zheng et al., 2010). Within the SO, we found reductions in dendritic spine density with morphine treatment, but not Tat expression. Acute morphine withdrawal also tended to reduce spine densities in the SO and SR. Previously, Tat reduced the overall density of spines by $11 \%$ along the apical dendrite in Golgi-impregnated CA1 pyramidal cells (Fitting et al., 2013). The numerical differences between Golgi versus biocytin studies may reflect differences in methodology or focus since spine densities within specific hippocampal layers or morphologic spine subtypes (described below) were not previously studied.

Subtle Tat and/or morphine-dependent rebalancing between excitatory and inhibitory synapses likely occurs within discrete areas of the hippocampal laminar structure, since Tat (Marks et al., 2016) and morphine (Drake and Milner, 1999, 2002) differentially affect distinct interneuronal subpopulations having unique regional distributions. In the SL-M, morphine withdrawal increased the numbers of stubby spines regardless of Tat and decreased thin/filopodial spines along the dendrites of Tat+ mice, indicating rapid alterations in synaptic plasticity along specific regions of the dendrite. Dendritic spine stability is susceptible to inflammation (Beroun et al., 2019) and opiate-induced or HIV-induced alterations in NeuroD signaling (Liao et al., 2005; Zheng et al., 2010; Yuferov et al., 2013). These morphologic changes can occur rapidly, as observed in an animal model of cocaine abuse (Stankeviciute et al., 2014). Mushroom spines, which are considered the most mature/stable form, were selectively reduced in the SR following 14-d Tat exposure. While the SR receives input from Shaffer collaterals, the SL-M receives distinct inputs of differentially processed spatial and non-spatial sensory information from the entorhinal cortex via the temporoammonic and perforant path fibers. The putative integrative mechanism formed by the interneuron network and pyramidal cells in CA1 can easily be unbalanced, leading to memory formation dysfunction (Kitamura et al., 2014, 2015; Marks et al., 2016, 2020). Although our findings show no differences in gephyrin puncta within pyramidal cell dendrites near the soma (Fig. 7), previously demonstrated increases in gephyrin levels do not discriminate pyramidal cells from other CA1 neuron types (Fitting et al., 2013). Selective spine losses in combination with disruptions to the inhibitory interneuron network (Fitting et al., 2013; Marks et al., 2016) are likely to contribute to decreased LTP (Bao et al., 2007; Fitting et al., 2013) and the altered CA1 pyramidal cell structure and function seen here.

\section{Morphine and Tat disrupt spatial memory}

HIV-1 Tat has previously been shown to attenuate spatial memory in the Barnes maze task (Carey et al., 2012; Kesby et al., 2016; Marks et al., 2016). Tat-mediated impairment of spatial memory coincided with reductions in pyramidal cell excitability at lower stimulating currents in the present study. Morphine treatment counteracted some of the negative effects of Tat, such as the proportion of time spent in incorrect quadrants but exacerbated the number of errors made by Tat + mice on a reversal probe trial and greatly increased the latency for all mice to find the escape hole. These findings may reveal cognitive 
distinctions between morphine's effects to potentially preserve aspects of Tat-impaired reference memory, while impeding novel search strategies. The notion that Tat and morphine can independently impair spatial memory is consistent with the minimal behavioral interactions observed in the current study (Zhu et al., 2011; Kitanaka et al., 2015; Kesby et al., 2016; Marks et al., 2016). Opioid-dependent individuals reportedly demonstrate hyper-connectivity in hippocampo-amygdalar memory circuits that may promote the recall of drug-associated cues (Zhang et al., 2017; Ma et al., 2020). This hyperactive associative circuitry may counterbalance the general effects of Tat (Basu and Siegelbaum, 2015; Roy et al., 2017; Sharifi et al., 2020).

The morphine implants used result in relatively high plasma levels, like those seen in OUD in which tolerance to high opioid dosages is typical. Higher morphine doses can generate a biphasic response in which activity oscillates before returning to baseline (Vasko and Domino, 1978). Tolerance to morphine's depressive effects develops more rapidly than to its stimulatory effects (Vasko and Domino, 1978; Ling et al., 1989; Le Marec et al., 2011), raising the possibility of locomotor confounds. In the present study, morphine treatment reduced overall velocity and initial distance traveled among Tat- mice, but increased distance traveled by Tat + mice. Differences in the distance traveled were not evident after day 1 , but we cannot rule out the contribution of motor influences given the high dose of morphine used in the present study, particularly during the first few days of exposure, while mice are still developing tolerance to the drug.

The collective findings suggest that the structure and function of CA1 pyramidal cells are dramatically influenced by morphine exposure. The presence of an additional stressor such as Tat may enhance the destabilizing effects of fluctuating morphine levels. While the striatum tends to display additive or synergistic interactions, Tat and morphine acted more independently and occasionally seemed to counteract each other in the hippocampus. Rapid alterations in pyramidal cell structure and function in response to opiate withdrawal underscore the potential importance of opiate pharmacokinetics and the sustained consequences of fluctuating drug levels (as seen in OUD) in driving the pathobiology of opiate abuse-neuroHIV comorbidity. The nuanced regional effects of HIV and opioid drugs open exciting questions on the extent to which network level effects on behavioral dysfunction are driven by the unique interplay of pathologic interactions and counteractive processes in distinct brain regions, and whether the counteractive effects can be used as a treatable target.

\section{References}

Anthony IC, Norrby KE, Dingwall T, Carnie FW, Millar T, Arango JC, Robertson R, Bell JE (2010) Predisposition to accelerated Alzheimer-related changes in the brains of human immunodeficiency virus negative opiate abusers. Brain 133:3685-3698.

Bao G, Kang L, Li H, Li Y, Pu L, Xia P, Ma L, Pei G (2007) Morphine and heroin differentially modulate in vivo hippocampal LTP in opiate-dependent rat. Neuropsychopharmacology 32:1738-1749.
Barnes CA (1979) Memory deficits associated with senescence: a neurophysiological and behavioral study in the rat. J Comp Physiol Psychol 93:74-104.

Basu J, Siegelbaum SA (2015) The corticohippocampal circuit, synaptic plasticity, and memory. Cold Spring Harb Perspect Biol 7: a021733.

Beroun A, Mitra S, Michaluk P, Pijet B, Stefaniuk M, Kaczmarek L (2019) MMPs in learning and memory and neuropsychiatric disorders. Cell Mol Life Sci 76:3207-3228.

Bogulavsky JJ, Gregus AM, Kim PT, Costa AC, Rajadhyaksha AM, Inturrisi CE (2009) Deletion of the glutamate receptor 5 subunit of kainate receptors affects the development of morphine tolerance. J Pharmacol Exp Ther 328:579-587.

Borjkhani M, Bahrami F, Janahmadi M (2018) Computational modeling of opioid-induced synaptic plasticity in hippocampus. PLoS One 13:e0193410.

Bourne JN, Harris KM (2011) Coordination of size and number of excitatory and inhibitory synapses results in a balanced structural plasticity along mature hippocampal CA1 dendrites during LTP. Hippocampus 21:354-373.

Bruce-Keller AJ, Chauhan A, Dimayuga FO, Gee J, Keller JN, Nath A (2003) Synaptic transport of human immunodeficiency virus-Tat protein causes neurotoxicity and gliosis in rat brain. $\mathrm{J}$ Neurosci 23:8417-8422.

Bruce-Keller AJ, Turchan-Cholewo J, Smart EJ, Geurin T, Chauhan A, Reid R, Xu R, Nath A, Knapp PE, Hauser KF (2008) Morphine causes rapid increases in glial activation and neuronal injury in the striatum of inducible HIV-1 Tat transgenic mice. Glia 56:14141427.

Byrd DA, Fellows RP, Morgello S, Franklin D, Heaton RK, Deutsch R, Atkinson JH, Clifford DB, Collier AC, Marra CM, Gelman B, McCutchan JA, Duarte NA, Simpson DM, McArthur J, Grant I; CHARTER Group (2011) Neurocognitive impact of substance use in HIV infection. J Acquir Immune Defic Syndr 58:154-162.

Byrd D, Murray J, Safdieh G, Morgello S (2012) Impact of opiate addiction on neuroinflammation in HIV. J Neurovirol 18:364-373.

Calhoun ME, Kurth D, Phinney AL, Long JM, Hengemihle J, Mouton PR, Ingram DK, Jucker M (1998) Hippocampal neuron and synaptophysin-positive bouton number in aging C57BL/6 mice. Neurobiol Aging 19:599-606.

Camara ML, Corrigan F, Jaehne EJ, Jawahar MC, Anscomb H, Koerner H, Baune BT (2013) TNF- $\alpha$ and its receptors modulate complex behaviours and neurotrophins in transgenic mice. Psychoneuroendocrinology 38:3102-3114.

Campbell EM, Jia H, Shankar A, Hanson D, Luo W, Masciotra S, Owen SM, Oster AM, Galang RR, Spiller MW, Blosser SJ, Chapman E, Roseberry JC, Gentry J, Pontones P, Duwve J, Peyrani P, Kagan RM, Whitcomb JM, Peters PJ, et al. (2017) Detailed transmission network analysis of a large opiate-driven outbreak of HIV infection in the United States. J Infect Dis 216:1053-1062.

Carey AN, Sypek El, Singh HD, Kaufman MJ, McLaughlin JP (2012) Expression of HIV-Tat protein is associated with learning and memory deficits in the mouse. Behav Brain Res 229:48-56.

Chefer VI, Shippenberg TS (2009) Augmentation of morphine-induced sensitization but reduction in morphine tolerance and reward in delta-opioid receptor knockout mice. Neuropsychopharmacology 34:887-898.

Christie MJ (2008) Cellular neuroadaptations to chronic opioids: tolerance, withdrawal and addiction. Br J Pharmacol 154:384-396.

Choii G, Ko J (2015) Gephyrin: a central GABAergic synapse organizer. Exp Mol Med 47:e158.

Cirino TJ, Harden SW, McLaughlin JP, Frazier CJ (2020) Region-specific effects of HIV-1 Tat on intrinsic electrophysiological properties of pyramidal neurons in mouse prefrontal cortex and hippocampus. J Neurophysiol 123:1332-1341.

Crawley JN, Paylor R (1997) A proposed test battery and constellations of specific behavioral paradigms to investigate the behavioral phenotypes of transgenic and knockout mice. Horm Behav 31:197-211. 
Denis CM, Morales KH, Wu Q, Metzger DS, Cheatle MD (2019) Association between diagnoses of chronic noncancer pain, substance use disorder, and HIV-related outcomes in people living with HIV. J Acquir Immune Defic Syndr 82 [Suppl 2]:S142-S147.

Dickens AM, Yoo SW, Chin AC, Xu J, Johnson TP, Trout AL, Hauser KF, Haughey NJ (2017) Chronic low-level expression of HIV-1 Tat promotes a neurodegenerative phenotype with aging. Sci Rep 7:7748.

Drake CT, Milner TA (1999) Mu opioid receptors are in somatodendritic and axonal compartments of GABAergic neurons in rat hippocampal formation. Brain Res 849:203-215.

Drake CT, Milner TA (2002) Mu opioid receptors are in discrete hippocampal interneuron subpopulations. Hippocampus 12:119136.

Ellis R, Langford D, Masliah E (2007) HIV and antiretroviral therapy in the brain: neuronal injury and repair. Nat Rev Neurosci 8:33-44.

Farahmandfar M, Zarrindast MR, Kadivar M, Karimian SM, Naghdi N (2011a) The effect of morphine sensitization on extracellular concentrations of GABA in dorsal hippocampus of male rats. Eur $\mathrm{J}$ Pharmacol 669:66-70.

Farahmandfar M, Karimian SM, Zarrindast MR, Kadivar M, Afrouzi H, Naghdi N (2011b) Morphine sensitization increases the extracellular level of glutamate in CA1 of rat hippocampus via $\mu$-opioid receptor. Neurosci Lett 494:130-134.

Fauci AS, Redfield RR, Sigounas G, Weahkee MD, Giroir BP (2019) Ending the HIV epidemic: a plan for the United States. JAMA 321:844-845.

Fitting S, Xu R, Bull C, Buch SK, El-Hage N, Nath A, Knapp PE, Hauser KF (2010a) Interactive comorbidity between opioid drug abuse and HIV-1 Tat. Am J Pathol 177:1397-1410.

Fitting S, Zou S, Chen W, Vo P, Hauser KF, Knapp PE (2010b) Regional heterogeneity and diversity in cytokine and chemokine production by astroglia: differential responses to HIV-1 Tat, gp120, and morphine revealed by multiplex analysis. J Proteome Res 9:1795-1804.

Fitting S, Ignatowska-Jankowska BM, Bull C, Skoff RP, Lichtman AH, Wise LE, Fox MA, Su J, Medina AE, Krahe TE, Knapp PE, Guido W, Hauser KF (2013) Synaptic dysfunction in the hippocampus accompanies learning and memory deficits in human immunodeficiency virus type- 1 Tat transgenic mice. Biol Psychiatry 73:443-453

Fitting S, Knapp PE, Zou S, Marks WD, Bowers MS, Akbarali HI, Hauser KF (2014) Interactive HIV-1 Tat and morphine-induced synaptodendritic injury is triggered through focal disruptions in $\mathrm{Na}^{+}$influx, mitochondrial instability, and $\mathrm{Ca}^{2+}$ overload. $\mathrm{J}$ Neurosci 34:12850-12864.

Fitting S, Ngwainmbi J, Kang M, Khan FA, Stevens DL, Dewey WL, Knapp PE, Hauser KF, Akbarali HI (2015) Sensitization of enteric neurons to morphine by HIV-1 Tat protein. Neurogastroenterol Motil 27:468-480.

Fitting S, Stevens DL, Khan FA, Scoggins KL, Enga RM, Beardsley PM, Knapp PE, Dewey WL, Hauser KF (2016) Morphine tolerance and physical dependence are altered in conditional HIV-1 Tat transgenic mice. J Pharmacol Exp Ther 356:96-105.

Fitting S, McRae M, Hauser KF (2020) Opioid and neuroHIV comorbidity - current and future perspectives. J Neuroimmune Pharmacol 15:584-627.

Francesconi W, Berton F, Marcondes MCG (2018) HIV-1 Tat alters neuronal intrinsic excitability. BMC Res Notes 11:275.

Ghazi-Khansari M, Zendehdel R, Pirali-Hamedani M, Amini M (2006) Determination of morphine in the plasma of addicts in using Zeolite $Y$ extraction following high-performance liquid chromatography. Clin Chim Acta 364:235-238.

Gothard KM, Skaggs WE, Moore KM, McNaughton BL (1996) Binding of hippocampal CA1 neural activity to multiple reference frames in a landmark-based navigation task. J Neurosci 16:823835.

Green MV, Raybuck JD, Zhang X, Wu MM, Thayer SA (2019) Scaling synapses in the presence of HIV. Neurochem Res 44:234-246.
Hahn YK, Podhaizer EM, Farris SP, Miles MF, Hauser KF, Knapp PE (2015) Effects of chronic HIV-1 Tat exposure in the CNS: heightened vulnerability of males versus females to changes in cell numbers, synaptic integrity, and behavior. Brain Struct Funct 220:605623.

Hahn YK, Paris JJ, Lichtman AH, Hauser KF, Sim-Selley LJ, Selley DE, Knapp PE (2016) Central HIV-1 Tat exposure elevates anxiety and fear conditioned responses of male mice concurrent with altered $\mu$-opioid receptor-mediated G-protein activation and $\beta$-arrestin 2 activity in the forebrain. Neurobiol Dis 92:124-136.

Hargus NJ, Thayer SA (2013) Human immunodeficiency virus-1 Tat protein increases the number of inhibitory synapses between hippocampal neurons in culture. J Neurosci 33:17908-17920.

Harris KM, Jensen FE, Tsao B (1992) Three-dimensional structure of dendritic spines and synapses in rat hippocampus (CA1) at postnatal day 15 and adult ages: implications for the maturation of synaptic physiology and long-term potentiation. J Neurosci [erratum (1992) 12:following table of contents] 12:2685-2705.

Harrison JM, Allen RG, Pellegrino MJ, Williams JT, Manzoni OJ (2002) Chronic morphine treatment alters endogenous opioid control of hippocampal mossy fiber synaptic transmission. J Neurophysiol 87:2464-2470.

Hauser KF, Fitting S, Dever SM, Podhaizer EM, Knapp PE (2012) Opiate drug use and the pathophysiology of neuroAIDS. Curr HIV Res 10:435-452.

Hiratani N, Fukai T (2017) Detailed dendritic excitatory/inhibitory balance through heterosynaptic spike-timing-dependent plasticity. J Neurosci 37:12106-12122.

Kesby JP, Markou A, Semenova S; TMARC Group (2016) Effects of HIV/TAT protein expression and chronic selegiline treatment on spatial memory, reversal learning and neurotransmitter levels in mice. Behav Brain Res 311:131-140.

Keutmann MK, Gonzalez R, Maki PM, Rubin LH, Vassileva J, Martin EM (2017) Sex differences in HIV effects on visual memory among substance-dependent individuals. J Clin Exp Neuropsychol 39:574-586.

Kitamura T, Pignatelli M, Suh J, Kohara K, Yoshiki A, Abe K, Tonegawa S (2014) Island cells control temporal association memory. Science 343:896-901.

Kitamura T, Sun C, Martin J, Kitch LJ, Schnitzer MJ, Tonegawa S (2015) Entorhinal cortical ocean cells encode specific contexts and drive context-specific fear memory. Neuron 87:1317-1331.

Kitanaka J, Kitanaka N, Hall FS, Fujii M, Goto A, Kanda Y, Koizumi A, Kuroiwa H, Mibayashi S, Muranishi Y, Otaki S, Sumikawa M, Tanaka K, Nishiyama N, Uhl GR, Takemura M (2015) Memory impairment and reduced exploratory behavior in mice after administration of systemic morphine. J Exp Neurosci 9:27-35.

Kovacs GG, Horvath MC, Majtenyi K, Lutz MI, Hurd YL, Keller E (2015) Heroin abuse exaggerates age-related deposition of hyperphosphorylated tau and p62-positive inclusions. Neurobiol Aging 36:3100-3107.

Kreek MJ (1987) Tolerance and dependence: implications for the pharmacological treatment of addiction. NIDA Res Monogr 76:5362

Kreek MJ (2001) Drug addictions. Molecular and cellular endpoints. Ann NY Acad Sci 937:2749.

Kreek MJ, LaForge KS, Butelman E (2002) Pharmacotherapy of addictions. Nat Rev Drug Discov 1:710-726.

Leibrand CR, Paris JJ, Jones AM, Masuda QN, Halquist MS, Kim WK, Knapp PE, Kashuba ADM, Hauser KF, McRae M (2019) HIV-1 Tat and opioids act independently to limit antiretroviral brain concentrations and reduce blood-brain barrier integrity. J Neurovirol 25:560-577.

Le Marec T, Marie-Claire C, Noble F, Marie N (2011) Chronic and intermittent morphine treatment differently regulates opioid and dopamine systems: a role in locomotor sensitization. Psychopharmacology (Berl) 216:297-303.

Lerner AM, Fauci AS (2019) Opioid injection in rural areas of the United States. JAMA 322:1041. 
Li ST, Matsushita M, Moriwaki A, Saheki Y, Lu YF, Tomizawa K, Wu HY, Terada H, Matsui H (2004) HIV-1 Tat inhibits long-term potentiation and attenuates spatial learning [corrected]. Ann Neurol 55:362-371.

Li W, Li Q, Wang Y, Zhu J, Ye J, Yan X, Li Y, Chen J, Liu J, Li Z, Wang W, Liu Y (2016) Methadone-induced damage to white matter integrity in methadone maintenance patients: a longitudinal self-control DTI Study. Sci Rep 6:19662.

Liao D, Lin H, Law PY, Loh HH (2005) Mu-opioid receptors modulate the stability of dendritic spines. Proc Natl Acad Sci USA 102:1725-1730.

Ling GS, Paul D, Simantov R, Pasternak GW (1989) Differential development of acute tolerance to analgesia, respiratory depression, gastrointestinal transit and hormone release in a morphine infusion model. Life Sci 45:1627-1636.

Liu F, Jiang H, Zhong W, Wu X, Luo J (2010) Changes in ensemble activity of hippocampus CA1 neurons induced by chronic morphine administration in freely behaving mice. Neuroscience 171:747-759.

Lucas GM, Gebo KA, Chaisson RE, Moore RD (2002) Longitudinal assessment of the effects of drug and alcohol abuse on HIV-1 treatment outcomes in an urban clinic. AIDS 16:767-774.

Ma Q, Fu Y, Cao Z, Shao D, Song J, Sheng H, Yang L, Cui D, Chen M, Zhao F, Luo MH, Lai B, Zheng P (2020) A Conditioningstrengthened circuit from CA1 of dorsal hippocampus to basolateral amygdala participates in morphine-withdrawal memory retrieval. Front Neurosci 14:646.

Magnuson DS, Knudsen BE, Geiger JD, Brownstone RM, Nath A (1995) Human immunodeficiency virus type 1 tat activates non- $N$ methyl-D- aspartate excitatory amino acid receptors and causes neurotoxicity. Ann Neurol 37:373-380.

Maki PM, Cohen MH, Weber K, Little DM, Fornelli D, Rubin LH, Perschler P, Gould F, Martin E (2009) Impairments in memory and hippocampal function in HIV-positive vs HIV-negative women: a preliminary study. Neurology 72:1661-1668.

Maragos WF, Tillman P, Jones M, Bruce-Keller AJ, Roth S, Bell JE, Nath A (2003) Neuronal injury in hippocampus with human immunodeficiency virus transactivating protein, Tat. Neuroscience 117:43-53.

Marks WD, Paris JJ, Schier CJ, Denton MD, Fitting S, McQuiston AR, Knapp PE, Hauser KF (2016) HIV-1 Tat causes cognitive deficits and selective loss of parvalbumin, somatostatin, and neuronal nitric oxide synthase expressing hippocampal CA1 interneuron subpopulations. J Neurovirol 22:747-762.

Marks WD, Yamamoto N, Kitamura T (2020) Complementary roles of differential medial entorhinal cortex inputs to the hippocampus for the formation and integration of temporal and contextual memory (systems neuroscience). Eur J Neurosci. Advance online publication. Retrieved Apr 11, 2020. doi: 10.1111/ejn.14737.

McArthur JC, Steiner J, Sacktor N, Nath A (2010) Human immunodeficiency virus-associated neurocognitive disorders: mind the gap. Ann Neurol 67:699-714.

McQuiston AR (2007) Effects of mu-opioid receptor modulation on $\mathrm{GABA}_{\mathrm{B}}$ receptor synaptic function in hippocampal CA1. J Neurophysiol 97:2301-2311.

McQuiston AR (2008) Layer selective presynaptic modulation of excitatory inputs to hippocampal cornu Ammon 1 by mu-opioid receptor activation. Neuroscience 151:209-221.

McQuiston AR, Saggau P (2003) Mu-opioid receptors facilitate the propagation of excitatory activity in rat hippocampal area CA1 by disinhibition of all anatomical layers. J Neurophysiol 90:19361948.

Megías M, Emri Z, Freund TF, Gulyás Al (2001) Total number and distribution of inhibitory and excitatory synapses on hippocampal CA1 pyramidal cells. Neuroscience 102:527-540.

Meyer VJ, Rubin LH, Martin E, Weber KM, Cohen MH, Golub ET, Valcour V, Young MA, Crystal H, Anastos K, Aouizerat BE, Milam J, Maki PM (2013) HIV and recent illicit drug use interact to affect verbal memory in women. J Acquir Immune Defic Syndr 63:67-76.
Mouton PR (2002) Principles and practices of unbiased stereology: an introduction for bioscientists. Baltimore: The Johns Hopkins University Press.

Mouton PR (2014) Neurostereology: Unbiased Stereology of Neural Systems. New York: Wiley Blackwell.

Nath A, Hauser KF, Wojna V, Booze RM, Maragos W, Prendergast M, Cass W, Turchan JT (2002) Molecular basis for interactions of HIV and drugs of abuse. J Acquir Immune Defic Syndr 31 [Suppl 2]:S62-S69.

Ochs SM, Dorostkar MM, Aramuni G, Schön C, Filser S, Pöschl J, Kremer A, Van Leuven F, Ovsepian SV, Herms J (2015) Loss of neuronal GSK3 $\beta$ reduces dendritic spine stability and attenuates excitatory synaptic transmission via $\beta$-catenin. Mol Psychiatry 20:482-489.

Pelkey KA, Chittajallu R, Craig MT, Tricoire L, Wester JC, McBain CJ (2017) Hippocampal GABAergic Inhibitory Interneurons. Physiol Rev 97:1619-1747.

Piepenbrink MS, Samuel M, Zheng B, Carter B, Fucile C, Bunce C, Kiebala M, Khan AA, Thakar J, Maggirwar SB, Morse D, Rosenberg AF, Haughey NJ, Valenti W, Keefer MC, Kobie JJ (2016) Humoral dysregulation associated with increased systemic inflammation among injection heroin users. PLoS One 11: e0158641.

Ramage SN, Anthony IC, Carnie FW, Busuttil A, Robertson R, Bell JE (2005) Hyperphosphorylated tau and amyloid precursor protein deposition is increased in the brains of young drug abusers. Neuropathol Appl Neurobiol 31:439-448.

Raybuck JD, Hargus NJ, Thayer SA (2017) A GluN2B-selective NMDAR antagonist reverses synapse loss and cognitive impairment produced by the HIV-1 protein Tat. J Neurosci 37:78377847.

Reisine T, Pasternak G (1996) 521-557. Opioid analgesics and antagonists. In: The pharmacological basis of therapeutics (Hardman JG, Gilman AG, Limbird LE, eds), Ed 9. New York: McGraw-Hill Professional.

Robinson TE, Gorny G, Savage VR, Kolb B (2002) Widespread but regionally specific effects of experimenter- versus self-administered morphine on dendritic spines in the nucleus accumbens, hippocampus, and neocortex of adult rats. Synapse 46:271-279.

Roy DS, Kitamura T, Okuyama T, Ogawa SK, Sun C, Obata Y, Yoshiki A, Tonegawa S (2017) Distinct neural circuits for the formation and retrieval of episodic memories. Cell 170:1000-1012.e19.

Saylor D, Dickens AM, Sacktor N, Haughey N, Slusher B, Pletnikov M, Mankowski JL, Brown A, Volsky DJ, McArthur JC (2016) HIVassociated neurocognitive disorder-pathogenesis and prospects for treatment. Nat Rev Neurol 12:234-248.

Schier CJ, Marks WD, Paris JJ, Barbour AJ, McLane VD, Maragos WF, McQuiston AR, Knapp PE, Hauser KF (2017) Selective vulnerability of striatal D2 versus D1 dopamine receptor-expressing medium spiny neurons in HIV-1 Tat transgenic male mice. J Neurosci 37:5758-5769.

Sharifi KA, Rezayof A, Alijanpour S, Zarrindast MR (2020) GABA-cannabinoid interplays in the dorsal hippocampus and basolateral amygdala mediate morphine-induced amnesia. Brain Res Bull 157:61-68.

Siggins GR, Zieglgänsberger W (1981) Morphine and opioid peptides reduce inhibitory synaptic potentials in hippocampal pyramidal cells in vitro without alteration of membrane potential. Proc Natl Acad Sci USA 78:5235-5239.

Smail RC, Brew BJ (2018) HIV-associated neurocognitive disorder. Handb Clin Neurol 152:75-97.

Stankeviciute NM, Scofield MD, Kalivas PW, Gipson CD (2014) Rapid, transient potentiation of dendritic spines in context-induced relapse to cocaine seeking. Addict Biol 19:972-974.

Vasko MR, Domino EF (1978) Tolerance development to the biphasic effects of morphine on locomotor activity and brain acetylcholine in the rat. J Pharmacol Exp Ther 207:848-858.

Vassileva J, Ahn W-Y, Weber KM, Busemeyer JR, Stout JC, Gonzalez R, Cohen MH (2013) Computational modeling reveals 
distinct effects of HIV and history of drug use on decision-making processes in women. PLoS One 8:e68962.

Wersinger SR, Ginns El, O'Carroll AM, Lolait SJ, Young WS 3rd (2002) Vasopressin V1b receptor knockout reduces aggressive behavior in male mice. Mol Psychiatry 7:975-984.

West MJ, Slomianka L, Gundersen HJ (1991) Unbiased stereological estimation of the total number of neurons in the subdivisions of the rat hippocampus using the optical fractionator. Anat Rec 231:482-497.

Xu Q, Li WY, Guan Y (2013) Mu-opioidergic modulation differs in deep and superficial wide dynamic range dorsal horn neurons in mice. Neurosci Lett 549:157-162.

Yuferov V, Ho A, Morgello S, Yang Y, Ott J, Kreek MJ (2013) Expression of ephrin receptors and ligands in postmortem brains of HIV-infected subjects with and without cognitive impairment. J Neuroimmune Pharmacol 8:333-344.

Zhang Y, Li Q, Wen X, Cai W, Li G, Tian J, Zhang YE, Liu J, Yuan K, Zhao J, Wang W, Zhou Z, Ding M, Gold MS, Liu Y, Wang GJ (2017) Granger causality reveals a dominant role of memory circuit in chronic opioid dependence. Addict Biol 22:1068-1080.

Zheng H, Zeng Y, Chu J, Kam AY, Loh HH, Law PY (2010) Modulations of NeuroD activity contribute to the differential effects of morphine and fentanyl on dendritic spine stability. J Neurosci 30:8102-8110.

Zhu F, Yan CX, Zhao Y, Zhao Y, Li PP, Li SB (2011) Effects of pretraining morphine on spatial memory acquisition and retrieval in mice. Physiol Behav 104:754-760. 